\title{
A Review of Theoretical Analysis Techniques for Cracking and Corrosive Degradation of Film-Substrate Systems
}

\author{
M. H. Nazir * and Z. Khan * \\ *Bournemouth University \\ NanoCorr, Energy \& Modelling Research Group (NCEM) \\ Faculty of Science and Technology, Bournemouth, UK
}

\begin{abstract}
This paper contains a review of the most vital concepts regarding the analysis and design of film systems. Various techniques have been presented to analyse and predict the failure of films for all common types of failure: fracture, delamination, general yield, cathodic blistering, erosive and corrosive wear in both organic and inorganic films. Interfacial fracture or delamination is the loss of bonding strength of film from substrate, and is normally analysed based on the fracture mechanics concepts of bi-material systems. Therefore, keeping the focus of this review on bonding strength, the emphasis will be on the interfacial cracking of films and the corresponding stresses responsible for driving the delamination process. The bi-material characteristics of film systems make the nature of interfacial cracks as mixed mode, with cracks exhibiting various complex patterns such as telephone cord blisters. Such interfacial fracture phenomenon has been widely studied by using fracture mechanics based applicable analysis to model and predict the fracture strength of interface in film systems. The incorporation of interfacial fracture mechanics concepts with the thermodynamics/diffusion concepts further leads to the development of corrosive degradation theories of film systems such as cathodic blistering. This review presents the suggestions for improvements in existing analysis techniques to overcome some of the limitations in film failure modelling. This comprehensive review will help researchers, scientists, and academics to understand, develop and improve the existing models and methods of film-substrate systems.
\end{abstract}

Keywords: Film Failure; Film cracking; Interfacial cracking; Corrosion; Cathodic delamination; Cathodic blistering; Tribo-corrosion

Table of Contents

Abstract 1

Table of Contents.

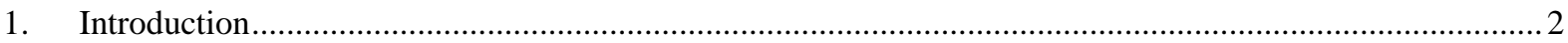

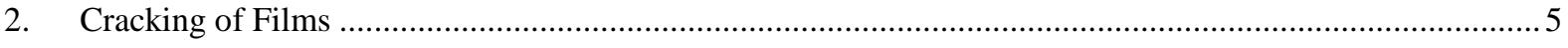

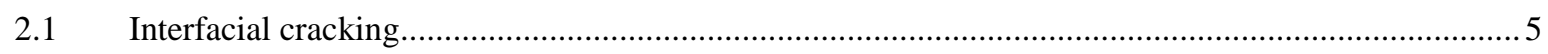

2.1.1 Fracture mechanics concepts for bi-material system ....................................................... 6

2.1.2 General loading concepts for film-substrate system ................................................... 7

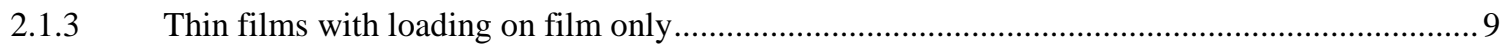

2.1.4 Configurational stability of the circular buckle delamination ................................................. 11

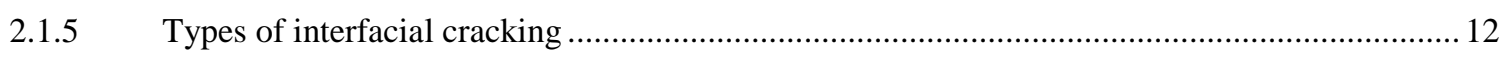

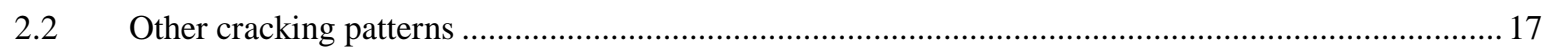

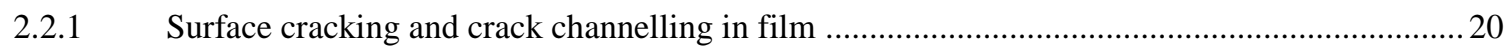

2.2.2 Crack in film with tip in substrate and spalling ......................................................... 21

2.3 Analysis for the case 'no pre-exiting interfacial crack exist' - Free edge singularity problem ...........22

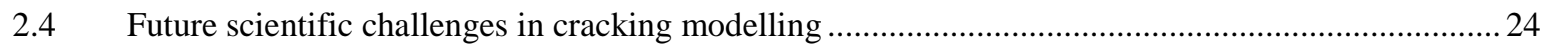




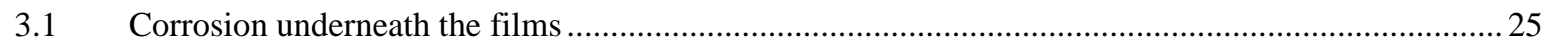

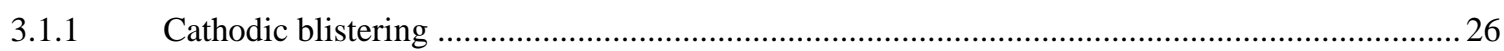

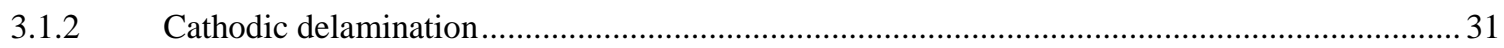

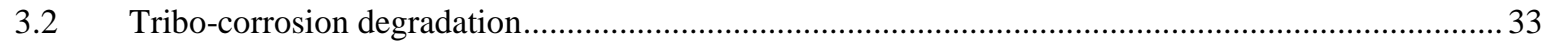

3.3 Future scientific challenges in degradation modelling ....................................................... 36

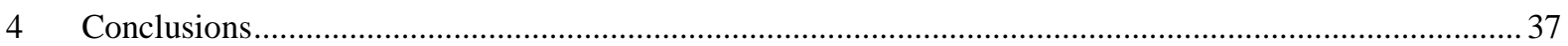

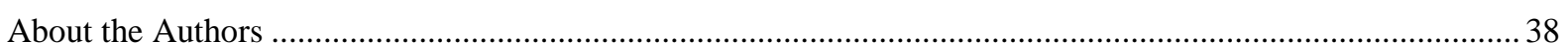

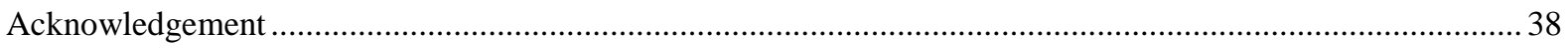

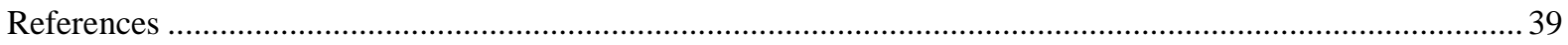

\section{Introduction}

Films bonded to substrates present a key element in many applications such as electronic semiconductor devices, thermal sensing devices, magnetic recording media, optical filters, parts with protective (anticorrosion) coatings, etc. Although there are various distinct types of films, most of them are broadly categorised as either organic or inorganic films. Organic films are normally applied in liquid form by using spray gun or brush. A special case is the exemption of powder films that are applied using electrostatic equipment and then sintered to form a continuous film. Inorganic films are normally metallic or ceramic based. Some important examples include thin films (e.g. Titanium nitride) which are normally applied using physical or chemical vapour deposition (PVD or CVD), conversion films (e.g. phosphate) and plasma sprayed films. The broad classification of films on the basis of deposition techniques along with their corresponding failures is shown in fig. 1.

The majority of film related failures can be attributed to six primary causes (i) Improper surface preparation and pre-treatment processes (ii) Improper film selection (iii) Improper application (iv) Improper drying and curing (v) Lack of protection against water and aqueous systems and (vi) Mechanical damage. The common causes of film failure which are mentioned above can result in several forms of failure in both organic and inorganic films as shown in fig. 1 .

There are several modes of failures within the context of structural integrity, including thin film deterioration which includes stress corrosion cracking (SSC), corrosion fatigue (CF), microbial corrosion, crevice corrosion and other conventional types. Electrochemical processes or applied static or dynamic loading lead to cause damage to large structures, installations, process equipment, pressure vessels and mobile assets of high value. The scope of this review includes failures of thin films which experience electrochemical processes in combination with mechanical loading aided by the influence of atmospheric quality. Previous work [1-9] has extensively studied the structural integrity issues from a multidisciplinary perspective that combines conventional corrosion in an environment where structures, products and components are also experiencing external applied load in conjunction with varying precipitations along with thermal gradient and the role of residual stresses. Combination of the above, poses significant challenges in terms of accurate modelling and simulation due to these ultra-complicated failure mechanisms. Therefore a comprehensive study was needed to solve immediate industrial problems faced during various applications and to provide design solutions for durability. The scope of this review however does not include certain aspects as microbial corrosion purely from the applications viewpoint.

Various films at nano scale have been designed and developed during the current and previous researches which fully incorporate durability issues. The corrosion resistance, tribological performance and film characteristics have been reported [10-13]. The crystalline structure of film materials and thin film porosity are 
not subjects of this review as the phenomenon of corrosion diffusing species through micro cracks in thin films have been reported [14-21] in detail.

Although there are many types of film failure but the focus of this review will be on two most important types i.e. cracking and corrosive degradation of films.

- Cracking:

Mechanics and mechanism of cracking in films, substrates and interfaces of film-substrate systems

- Corrosive Degradation:

Interfacial film failure analysis under corrosive conditions i.e. cathodic delamination, cathodic blistering and tribo-corrosion conditions i.e. wear-corrosion

The above failures are highlighted as yellow in fig. 1. These failures are a big challenge for material scientists from the last four decades due to the increasing diversity of film categories. It can be seen from fig. 1 that both organic and inorganic films with their respective categories exhibit cracking and corrosion failures. Tribo corrosion is mainly observed in inorganic thin ceramic films such as titanium nitride.

The performance and reliability of film-substrate system structures are largely determined by the bonding strength and the fracture resistance of films. The modelling techniques of film strength and fracture present an important basis for the analysis of film-substrate systems which prove useful for the improvement of quality and reliability of many electronic and mechanical technologies. In this review, the successes and failures of modelling techniques of cracking and corrosive degradation in films have been discussed. At first, cracking models of films are reviewed in detail including: interfacial cracking, surface cracking, crack channelling in film, crack in film with tip in substrate and spalling. Then degradation models of films are discussed which simulate the failures of films when they are subjected to corrosive and tribo-corrosive conditions. Another important aspect of this review is that it discusses some of the main modelling limitations of cracking and degradation in films, as well as prospects for future work. The limitations and future work under each part is discussed separately.

The literature on modelling of cracking and degradation of film-substrate systems is particularly rich. Searches from Web of Knowledge on $28^{\text {th }}$ July 2016 revealed the significant increase of the number of publications and citations on film cracking and degradation in recent years as demonstrated in fig. 2 respectively. Other interesting statistics from the above search included the average citation per item of $15.69,16.27$ and the hindex of 63, 48 for cracking and degradation of films respectively. There are almost 10,000 articles published in these areas over the last 20 years, so a critical overview would be very helpful for the researchers, which is main goal of this review.

This review highlights the modelling methods and results of films performance in areas of cracking and degradation. It will identify all major models that have been developed over a period of time for the performance analysis of films. The incorporation of improved experimental and simulation methods which are suggested in this review can benefit to overcome some of the limitations in existing film-substrate models. The inclusion of these methods can provide with a comprehensive framework which can help to analyse many interdisciplinary complex film failure problems which currently seem to be not possible with the existing models. However, the development of models with accurate and reliable predictions for film performance analysis is a complex subject with countless material, mechanical, mechanics, environmental, stochastic parameters and the subject still demands greater attention from world-leading scientists and best research groups for qualitative improvements and appropriate developments. The background of authors is mentioned at the end of this paper. 


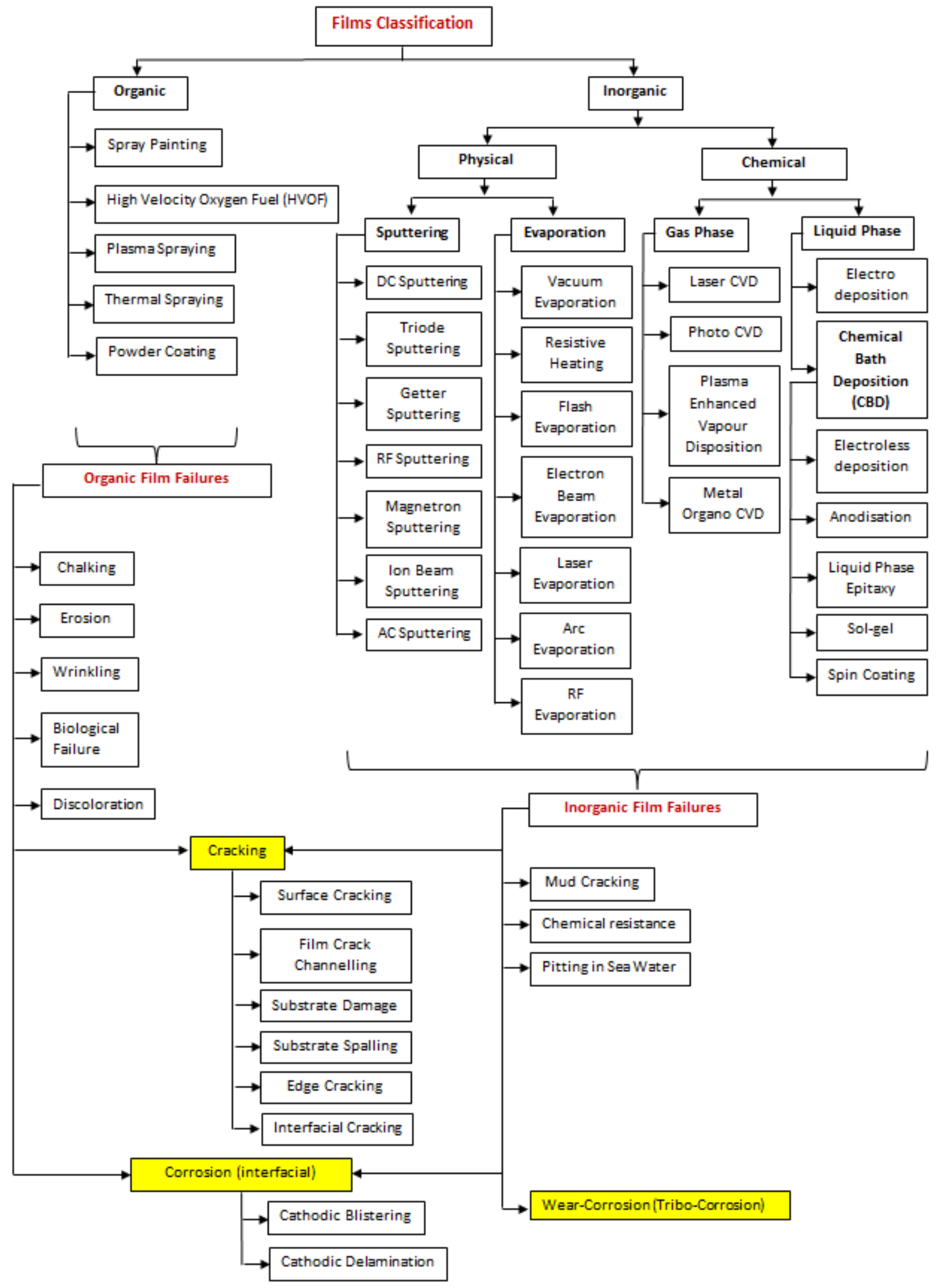

Figure 1. Flow diagram showing the broad classification of films on the basis of deposition techniques along with their corresponding failures 


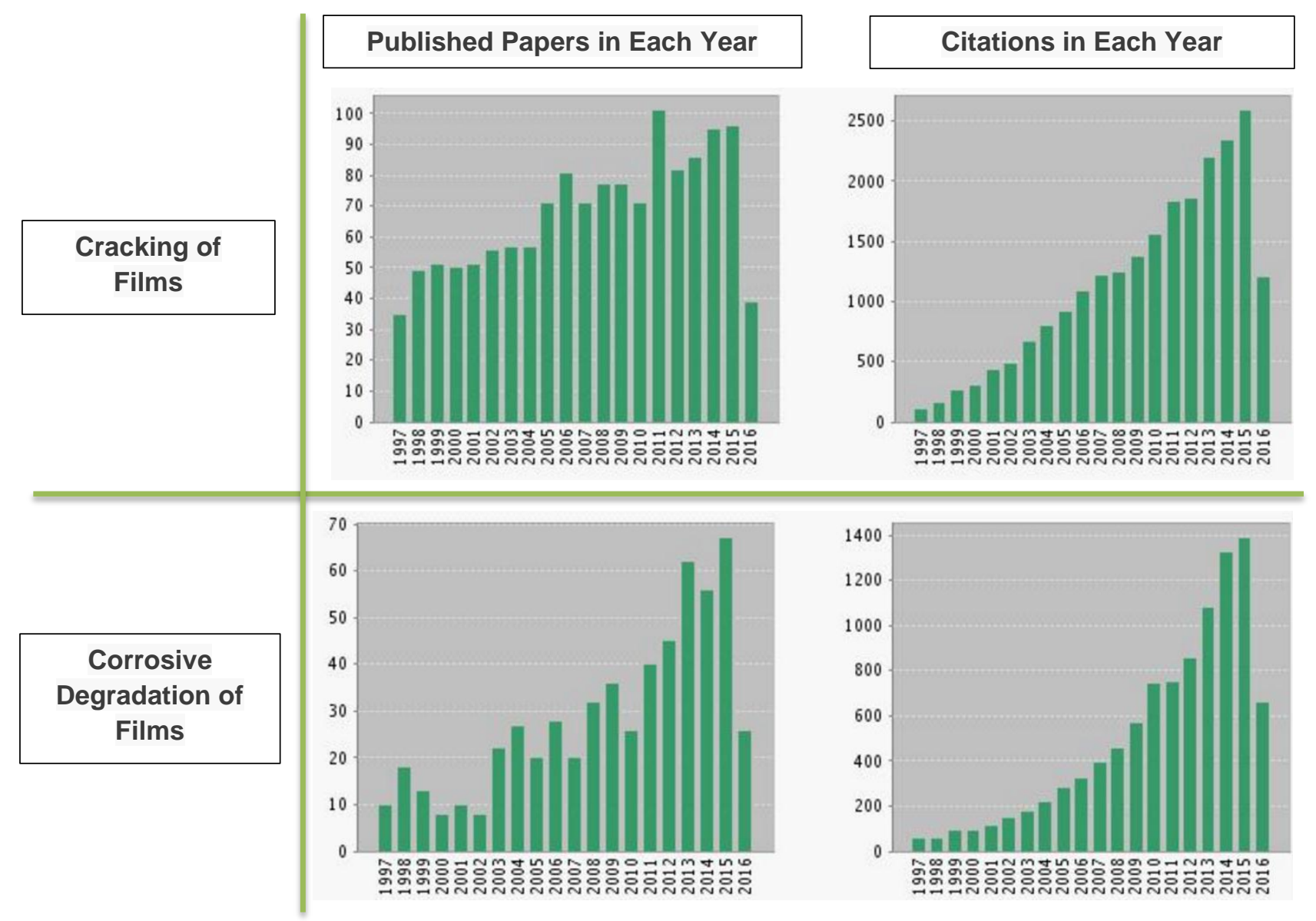

Figure 2. Number of published papers and the citations against year searched from Web of Knowledge on $28^{\text {th }}$ July 2016.

\section{Cracking of Films}

A thin film, coating, or surface layer supported on a substrate is typically subjected to appreciable residual stress which can result in failure in any of numerous ways: delamination, fracture, general yield and erosive wear. Delamination is the loss of bonding strength (adhesion) of film from substrate, and for the case of compressive stresses in film, usually blistering is involved. Normal causes of delamination include: thermal expansion mismatch stresses, residual stresses, impact, indentation or contact stresses and environmental attack. Fracture is the propagation of crack in film rather than propagation along the interface between the film and substrate (delamination). Film fracture usually results due to contact or impact phenomena.

Organic films are usually soft and are generally applied to hard surfaces. In contrast, inorganic films are hard and normally applied to safeguard softer substrates from environmental attack or wear. Based on this, one can make certain observations in the fracture or stress analysis of films. In this section, the discussion will be on mechanics of films. In order to keep the focus of this work on bonding strength, the emphasis will be on interfacial cracking of films and the determination of stresses that derive the delamination process.

\subsection{Interfacial cracking}

Cracking, weather along the film-substrate interface (delamination) or in the film itself, is one of the most vital processes responsible for film failure and evolves as a result of stresses that are created by different effects for example thermal expansion mismatch, particle impact or indentation and film shrinking or swelling. Film bonded to substrate is referred as a bi-material system. The system is normally characterised by huge changes in properties in the interfacial region of film and substrate. The problem further becomes complex due to the 
sensitivity of film-substrate interfacial bonding to pre-treatment (or contamination), the thickness of film, the properties of both the film and substrate resulting in complicated fracture mechanics modelling due to large number of different parameters.

The analyses in the proceeding sections assume the steady state propagation of already existing interfacial crack (i.e. pre-existing crack), and does not consider crack nucleation/initiation. However, the analysis for the case when no pre-existing interfacial crack exists will be separately discussed in section 2.3.

\subsubsection{Fracture mechanics concepts for bi-material system}

Interfacial cracking in a bi-material system involves decohesion of the film from substrate under the influence of compressive or tensile residual stress. Matthews and Klokholm performed the pioneering work on the fracture of thin films. However, the proper notation of fracture mechanics analysis for interfacial cracking failure was originally presented by Rice and utilised by Hutchinson and co-workers, and is selected because the equations get simplified to their Linear Elastic Fracture Mechanics (LEFM) forms if both materials are identical.

An interfacial crack in a bi-material system involves thermal mismatch (fig. 3). The mismatch can be defined in term of dimensionless Dandur's parameters . For the case of film on substrate, these parameters are defined as,

$$
\alpha=\frac{\mu_{F}\left(k_{S}+1\right)-\mu_{S}\left(k_{F}+1\right)}{\mu_{F}\left(K_{S}+1\right)+\mu_{S}(F+1)}
$$

and

$$
\boldsymbol{\beta}=\frac{\mu_{\mathrm{C}}\left(\mathbf{k}_{\mathrm{S}}-\mathbf{1}\right)-\mu_{\mathrm{S}}\left(\mathbf{k}_{\mathrm{C}}-\mathbf{1}\right)}{\mu_{\mathrm{C}}\left(\mathbf{k}_{\mathrm{S}}+\mathbf{1}\right)+\mu_{\mathrm{S}}\left(\mathbf{k}_{\mathrm{C}}+\mathbf{1}\right)}
$$

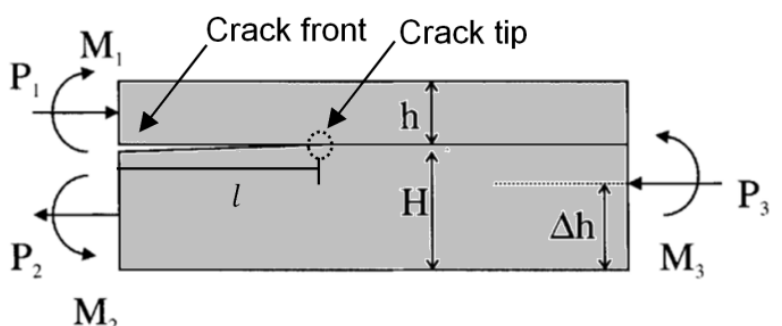

Figure 3. A schematic of the loading for a bi-material system having an interfacial crack [22]

Where the subscript $\mathrm{F}$ and $\mathrm{S}$ denote to the film and substrate respectively. Considering the plane strain conditions, then,

$$
\boldsymbol{k}_{C}=3-4 v_{c} \text { and } \boldsymbol{k}_{s}=3-4 v_{s}
$$

Where $\mu$ in eq. 2 is the shear modulus and $v$ in eq. 3 is the Poisson's ratio. The stresses on the interface of bimaterial directly at the crack front and at a distance $r$ from the crack tip, are gives as,

$$
\sigma_{22}+\mathbf{i} \sigma_{12}=\frac{K_{1}+i K_{2}}{\sqrt{(2 \pi r)}} \mathbf{r}^{i \varepsilon}
$$

Where, the parameter $\varepsilon$ is given by,

$$
\varepsilon=\frac{1}{2 \pi} \ln \left(\frac{1-\beta}{1+\beta}\right)
$$

and the conventional stress intensity factor $\mathrm{K}=\mathrm{K}_{1}+\mathrm{iK}_{2}$ has both real and imaginary parts that are identical to the conventional mode I and mode II stress intensity factors in LEFM. If, for example, the term $\mathrm{r}^{\mathrm{i} \varepsilon}$ was 
exempted, then eq. 4 would produce the mode I $\left(\sigma_{22}\right)$ and mode II $\left(\sigma_{12}\right)$ stress components at crack front, and $\mathrm{K}_{1}$ and $\mathrm{K}_{2}$ would simplify to $\mathrm{K}_{\mathrm{I}}$ and $\mathrm{K}_{\mathrm{II}}$ of classical LEFM. On the other hand, if $\beta \neq 0$, then term $\mathrm{r}^{\mathrm{i} \varepsilon}$ produces an oscillating singularity which makes the mode mix and normal stress intensity notions very complex. However, in reality, most of the normally utilised films and substrates possess a set of material properties producing non-zero $\beta$. An expression of mode-mix corresponding to characteristic crack length $l$ is [22].

$$
\psi=\tan ^{-1}\left[\frac{\operatorname{Im}\left(\mathrm{KI}^{\mathrm{ie}}\right)}{\left(\operatorname{Re}\left(\mathrm{Ki}^{\mathrm{ie}}\right)\right.}\right]=\tan ^{-1}\left(\frac{\mathrm{K}_{2}}{\mathrm{~K}_{1}}\right)=\tan ^{-1}\left(\frac{\sigma_{12}(\mathrm{r}=\mathrm{l})}{\sigma_{22}(\mathrm{r}=\mathrm{l})}\right)
$$

Where $\mathrm{K}$ represents the complex stress intentiy factor. Mode I crack is the one having zero shear stress $\sigma_{12}$ at a spacing $l$ infront of the crack tip, while a mode II crack has zero normal stess $\sigma_{22}$ at that particular location. For the case when elastic mismatch is negligible or $\varepsilon=0$, eq. 6 simplifies to the classical LEFM value.

$$
\Psi=\tan ^{-1}\left(\frac{\mathrm{K}_{\mathrm{II}}}{\mathrm{K}_{\mathrm{I}}}\right)
$$

The selection of the reference length $l$ is random and for the case of thin film, the film thickness $h$ is usually used. It is worth noting that the mode mix $\psi$ is directly affected by film's thickness, however eq. 6 reveals that data corresponding to distinct film thickness values can be correlated using the transformation law as [22],

$$
\Psi_{2}=\Psi_{1}+\varepsilon \ln \left(\frac{h_{2}}{h_{1}}\right)
$$

Where $h_{1}$ and $h_{2}$ are the two distinct film thicknesses which are being correlated.

Eq. 6 illustrates that $\psi$ can lie in the range $\pm 90^{\circ}$ when $\mathrm{K}_{1} \geq 0$ as $\mathrm{K}_{2}$ can have either positive or negative value subject to the sign of the shear stress $\sigma_{12}$. The relation between strain energy release rate $G$ [23] and $\mathrm{K}$ for interfacial cracking is [22].

$$
\mathbf{G}=\frac{1-\beta^{2}}{2}\left(\frac{1}{\overline{E_{1}}}+\frac{1}{\bar{E}_{2}}\right)\left(K_{1}^{2}+K_{2}^{2}\right)
$$

Where the subscripts ' 1 ' and ' 2 ' in the Elastic moduli relate to the materials on each side of the bi-material interface and the bars '- ' relate to the plane strain or the plane stress conditions,

$$
\begin{array}{ll}
\bar{E}=E & \text { plane stress } \\
\overline{\mathbf{E}}=\frac{\mathbf{E}}{{\mathbf{1 - \mathbf { v } ^ { 2 }}}} & \text { plane stress }
\end{array}
$$

This once more simplifies to the classical LEFM value for negligible elastic mismatch as,

$$
\mathbf{G}=\mathbf{G}_{\mathrm{I}}+\mathbf{G}_{\mathrm{II}}=\frac{\mathbf{K}^{2}}{\overline{\mathbf{E}}}=\frac{\mathbf{K}_{I}^{2}+\mathbf{K}_{\text {II }}^{2}}{\overline{\mathbf{E}}}
$$

Where $G_{I}$ is the mode I and $G_{I I}$ is the mode II component of strain energy release rate $G$.

\subsubsection{General loading concepts for film-substrate system}

Now we will proceed with the actual phase angles and stress intensity factors essential for the analysis of interfacial fracture mechanism of films. Consider the two elastic layers of a bi-layer cantilever beam having a crack at the interface between the two parallel layers (fig. 3). The loads at the boundaries of layers are applied at the centre of their respective beam and are measured in per unit width. The mode mix, stress intensity factor and strain energy release rate for the above crack can be measured in terms of the corresponding responses to loads at the boundaries of the layers. Here it is assumed that the shear deformations are negligible and the estimation of stress fields in the two layers can be performed by utilising the beam-theory approximation. The region at the right of the crack tip (fig. 3 ) is treated as a composite beam, such that the subsequent geometric parameters will be beneficial in developing fracture parameters: 


$$
\sum=\frac{\overline{\mathbf{E}}_{1}}{\overline{\mathbf{E}}_{2}}, \quad \boldsymbol{\eta}=\frac{\mathbf{h}}{\mathbf{H}}, \quad \Delta=\frac{1+2 \sum \boldsymbol{\eta}+\sum \eta^{2}}{2 \boldsymbol{\eta}\left(1+\sum \boldsymbol{\eta}\right)}
$$

The strain energy release rate $G$ which represents the interfacial toughness is measured by the difference in strain energy stored in the layers well behind and well ahead of the crack tip (fig. 3 ) in the per unit length per unit width as,

$$
G=\frac{1}{2 \bar{E}_{1}}\left(\frac{P_{1}^{2}}{h}+\frac{12 M_{1}^{2}}{h^{3}}\right)+\frac{1}{2 \bar{E}_{1}}\left(\frac{P_{2}^{2}}{H}+\frac{12 M_{2}^{2}}{H^{3}}-\frac{P_{3}^{2}}{A h}-\frac{M_{3}^{2}}{I^{3}}\right)
$$

Where $\mathrm{M}$ is the loading (moment/unit/length of the crack edge), $\mathrm{P}$ is the resultant stress-force/unit length of the crack edge acting on the film, I and A are the dimensionless moment of inertia and composite beam area respectively given by,

$$
\begin{gathered}
\mathbf{A}=\frac{1}{\eta}+\sum \\
I=\sum\left[\left(\Delta-\frac{1}{\eta}\right)^{2}-\left(\Delta-\frac{1}{\eta}\right)+\frac{1}{3}\right]+\frac{\Delta}{\eta}\left(\Delta-\frac{1}{\eta}\right)+\frac{1}{3 \eta^{3}} \\
P=P_{1}-C_{1} P_{3}-\frac{C_{2} M_{3}}{h}, \quad M=M_{1}-C_{3} M_{3}
\end{gathered}
$$

with

$$
\mathbf{C}_{1}=\frac{\Sigma}{\mathbf{A}}, \quad \mathbf{C}_{2}=\frac{\Sigma}{\mathrm{I}}\left(\frac{\mathbf{1}}{\eta}+\frac{\mathbf{1}}{\mathbf{2}}-\Delta\right), \quad \mathbf{C}_{3}=\frac{\Sigma}{12 \mathrm{I}}
$$

The corresponding complex stress intensity factor, which gives the information about the mode mix conditions, can be written as

$$
K=h^{i e} \sqrt{\left(\frac{1-\alpha}{1-\beta^{2}}\right)}\left(\frac{P}{\sqrt{2 h U}}-i e^{i \Upsilon} \frac{M}{\sqrt{2 h^{3} V}}\right) e^{i \omega}
$$

and

$$
\frac{1}{\mathrm{U}}=1+\sum \eta\left(4+6 \eta+3 \eta^{2}\right), \quad \frac{1}{\mathrm{v}}=12\left(1+\sum \eta^{3}\right), \quad \frac{\sin \Upsilon}{\sqrt{\mathrm{UV}}}=6 \sum \eta^{2}(1+\eta)
$$

By segregating the real and imaginary parts of eq. 18, it is possible to modify the eq. 6 by using $l=h$ for the phase angle describing the mode mix as,

$$
\Psi=\tan ^{-1} \frac{\sqrt{\frac{V}{U}}\left(\frac{P h}{M}\right) \sin \omega-\cos (\omega+\Upsilon)}{\sqrt{\frac{V}{U}}\left(\frac{P h}{M}\right) \cos \omega+\sin (\omega+\Upsilon)}
$$

It should be noted that, excluding $\omega$, the complete solution till this point has been evaluated by considering dimensions, linearity and geometry. However, the evaluation of $\omega$ requires hard solution of complex elastic problem initially solved by Hutchinson and Suo utilising the tabulation and integration methods of $\omega$ which is directly affected by $\alpha, \beta$ and $\eta$ [24]. The change in $\omega$ corresponding to $\alpha, \beta$ and $\eta$ for two special cases is shown in fig. 4. 


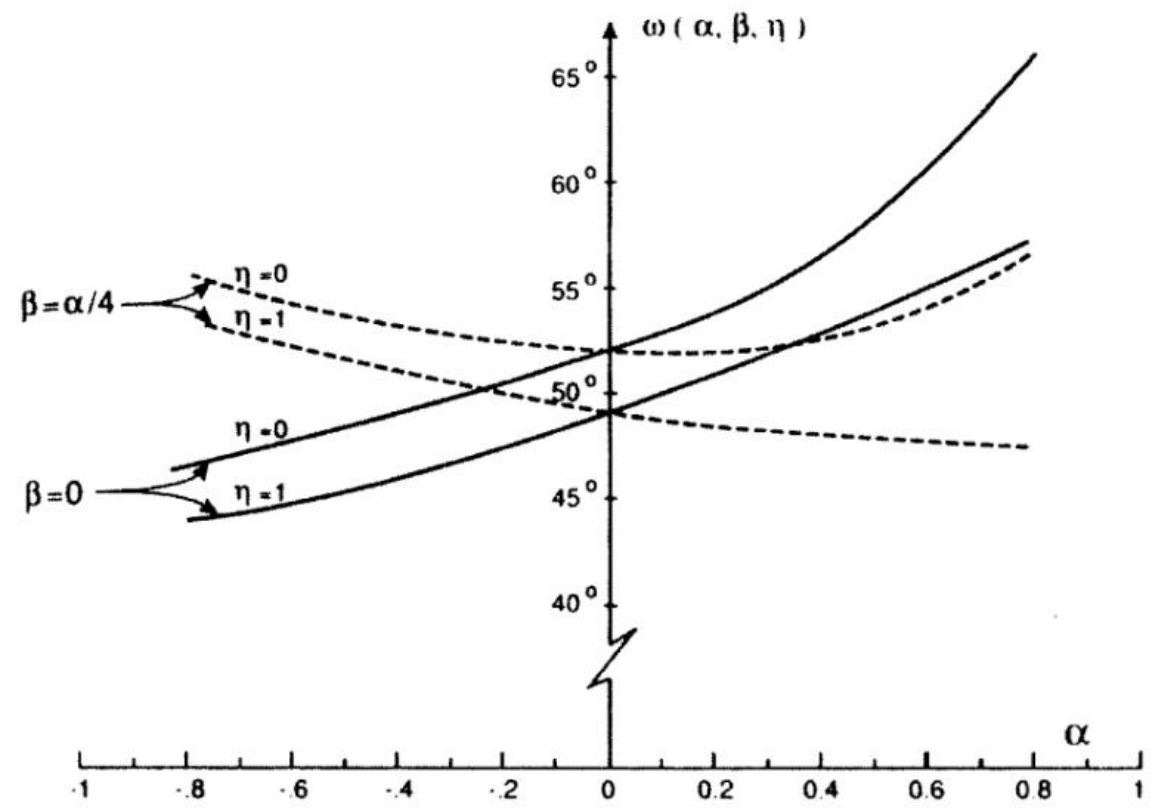

Figure 4. The function $\boldsymbol{\omega}(\alpha, \boldsymbol{\beta}, \boldsymbol{\eta})$ for two special cases of $\boldsymbol{\beta}[24]$

The above analysis is true for every condition of edge loads, provided that, the crack is along the interface and propagates in between the two elastic layers. The only important consideration is that the stress field in the layers be related as a function of edge loads (fig. 3). The above equations incorporated with the basic strength of materials approaches (for edge loads) make it possible to analyse a range of interfacial cracking problems. This way, the mode mix, applied stress intensity factor and energy release rate can be evaluated in terms of loads applied at a distance from the crack tip. These applied parameters are then correlated with their equivalent experimental data values (such as [25]) so as to determine the fracture loads.

\subsubsection{Thin films with loading on film only}

For the case of films (such as thin films) which are far thinner than the substrate, the equations in above section can be reduced by using $\eta=0$. Further simplification for the stress intensity, strain energy release rate and phase angle can be achieved by considering the applied load only on thin film (fig. 5). Such situation makes it appropriate for the analysis of the thin film problems of blistering, delamination and buckling delamination because of thermal mismatch stresses or other residual stresses. For these cases, the edge load on the thin film can be described in terms of mismatch in stresses, having zero loading of the substrate on the edge. For such specific case, $\mathrm{h} \ll \mathrm{H}, \mathrm{P}_{2}=\mathrm{M}_{2}=\eta=0$, therefore, eq. 13, 18 and 20 becomes respectively as,

$$
\begin{gathered}
G=6 \frac{1-v_{1}^{2}}{E_{1} h^{3}}\left(M_{1}^{2}+\frac{h^{2} P_{1}^{2}}{12}\right) \\
K=h^{i \varepsilon} 6\left(\frac{1-\alpha}{1-\beta^{2}}\right) \frac{1}{h^{\frac{3}{2}}}\left(\frac{h P_{1}}{\sqrt{12}}-i M_{1}\right) e^{i \omega} \\
\Psi=\tan ^{-1} \frac{\operatorname{lm}\left(K^{i \varepsilon}\right)}{\operatorname{Re}\left(K^{i \varepsilon}\right)}=\tan ^{-1} \frac{\cos \omega-\frac{h_{1}}{\sqrt{12} M_{1}} \sin \omega}{-\sin \omega-\frac{h P_{1}}{\sqrt{12} M_{1}} \cos \omega}
\end{gathered}
$$




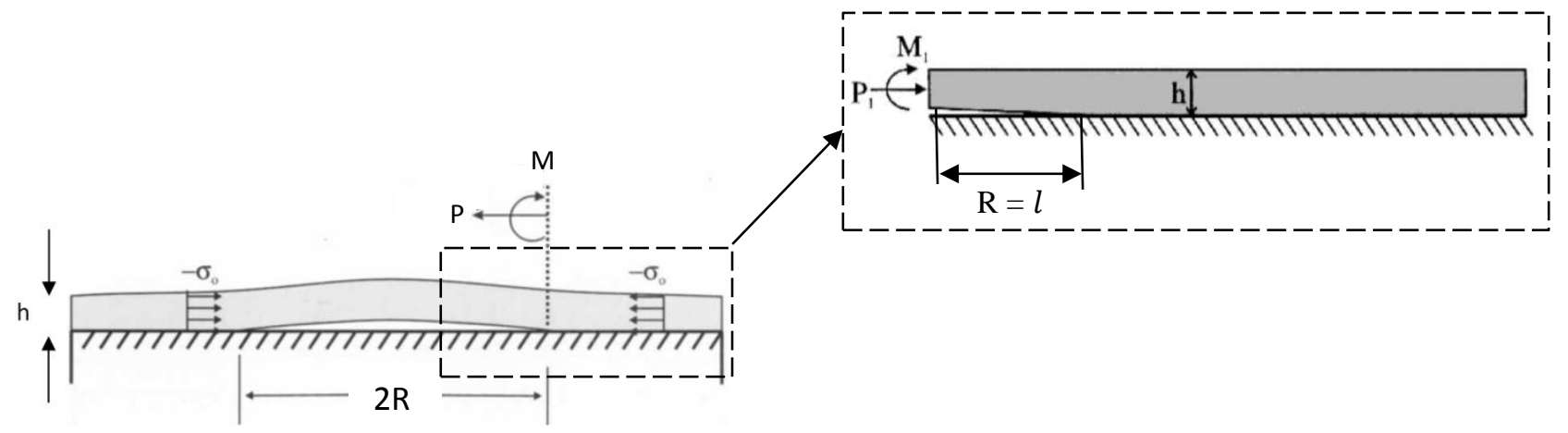

Figure 5. (Left) Buckling of film due to compressive residual stress for the case where substrate is much thicker compared to film, (Right) simplified edge loading [25]

Where $E_{1}$ and $v_{1}$ correspond to the film. The assumed direction of $M_{1}$ and $P_{1}$ are as shown in fig. 5. Eq. 23 shows that $\psi$ is affected by both the elastic mismatch through $\omega$ and the conditions at the edge of the crack only through the combination of terms $\left(\mathrm{hP}_{1}\right) /\left(\sqrt{12} \mathrm{M}_{1}\right)$. This combination, which also is only a function of film's Poisson's ratio, the ratio of delamination height of film $\boldsymbol{\delta}$ to film thickness $\mathrm{h}$ can be written as,

$$
\frac{\mathrm{hP}_{1}}{\sqrt{12} \mathrm{M}_{1}}=0.2486\left(1+v_{1}\right)\left(\frac{\delta}{\mathrm{h}}\right)
$$

and $\delta / \mathrm{h}$ is a function of applied stress $\sigma$ to the critical stress of film $\sigma_{c}$. Where $\sigma_{c}$ is the critical compressive stress which is required for the buckling.

$$
\frac{\delta}{h}=\sqrt{\left[\frac{1}{0.2473\left(1+v_{1}\right)+0.2231\left(1-v_{1}^{2}\right)}\left(\frac{\sigma}{\sigma_{c}}-1\right)\right]}
$$

The critical stress of film depends on film thickness $\mathrm{h}$ and other material properties as,

$$
\sigma_{c}=1.2235 \frac{E_{1}}{1-v_{1}^{2}}\left(\frac{h}{R}\right)^{2}
$$

Where $\mathrm{R}$ is one-half of the interfacial crack (delaminations) length (fig. 5). This explains the expected outcome, that why a thin film is more prone to interfacial buckling compared to a thick film. This outcome also explains the reason for possible blister propagation, as $\mathrm{R}$ grows in eq. 26, $\sigma_{c}$ reduces and consequently eq. 23 predicts that delamination propagates due to increase in crack driving force G. Moreover, the analysis of eq. 7 shows that with the growth of R, the mode II contribution increases. For example, for the case of zero elastic mismatch, $\omega=52.1^{\circ}$ and at $\sigma=\sigma_{\mathrm{c}}, \psi=-37.9^{0}$; whereas, when $\sigma=7.6 \sigma_{\mathrm{c}}$ then $\psi=-90^{\circ}$ (i. e. pure mode II). Since model II offers significantly higher fracture toughness compared to that in mode I, the propagating blister is stable and faces increasingly larger fracture toughness.

The parameter, stress to critical stress ratio $\sigma / \sigma_{\mathrm{c}}$ sets the criterion for blister initiation. For the blister to propagate, it must follow the criterion i.e. $\sigma / \sigma_{\mathrm{c}}>1$.

$$
\frac{\sigma}{\sigma_{c}}=0.8173\left(1-v_{1}^{2}\right) \frac{\sigma}{E_{1}}\left(\frac{R}{h}\right)^{2}
$$

Where $\mathrm{R}=l$ is the length of the crack from the crack tip to the crack edge. $\sigma / \sigma_{\mathrm{c}}$ may rise because of increase in delamination length $\mathrm{R}$ or to an increase in the unbuckled stress $\sigma$. It is worth noting up till now the elastic energy release rate $\mathrm{G}$ is significantly influenced by the $\sigma / \sigma_{c}$ ratio for various values of $\mathrm{v}_{1}$ as shown in fig. 6 . As can be seen that $\mathrm{G}$ increases monotonicity with $\sigma / \sigma_{c}$, and then stabilises. 


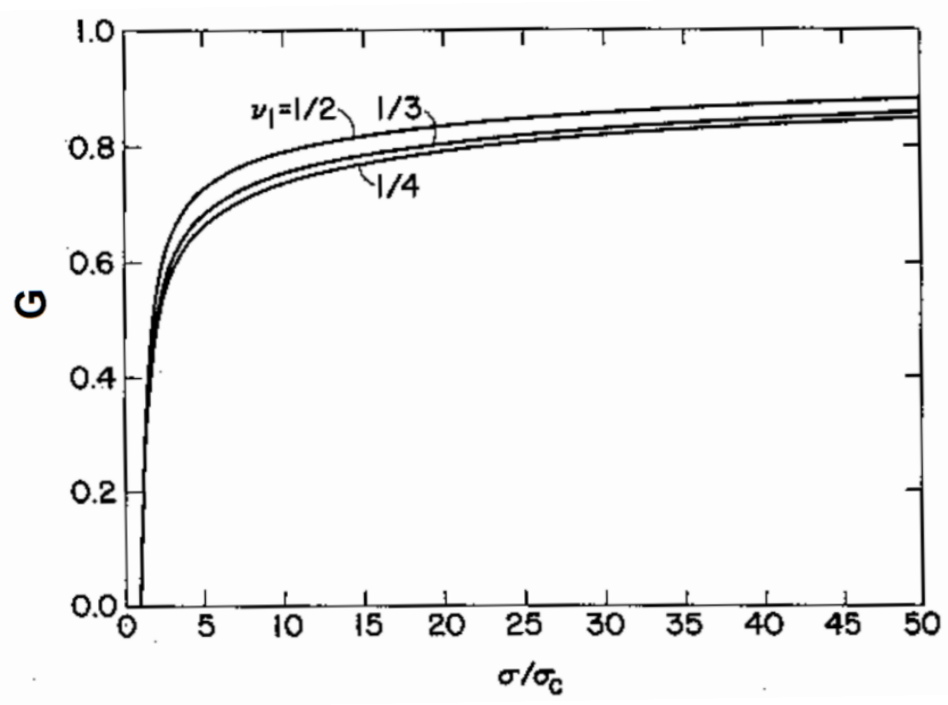

Figure 6. Strain elastic energy release rate during delamination as a function of $\boldsymbol{\sigma} / \boldsymbol{\sigma}_{\boldsymbol{c}}$ for various values of $\mathrm{v}_{1}$ [23]

\subsubsection{Configurational stability of the circular buckle delamination}

Now we will focus on the tendency of circular buckle delamination (fig. 7 (a)) to develop a non-circular shape (fig. 7 (b)). Two possibilities have been considered: the first possibility analysed is that when the interfacial crack front remain circular but the non-axisymmetric buckling evolves from the non-linear axisymmetric state. It was reported [23] that for the bifurcation in to non-axisymmetric mode (fig. 7 (b)), $\sigma / \sigma_{\mathrm{c}}$ should be equal to 55.6 for $\mathrm{v}_{1}=1 / 3$. The $\theta$ variation of the lowest mode is of the form $\cos \mathrm{n} \theta$ with $\mathrm{n}=8$. As different nonaxisymmetric behaviour is witnessed at various values of $\sigma / \sigma_{\mathrm{c}}$ in the proximity of 5 , therefore such behaviour is not a result of non-axisymmetric buckling.

Circular buckle

(axisymmetric buckling)
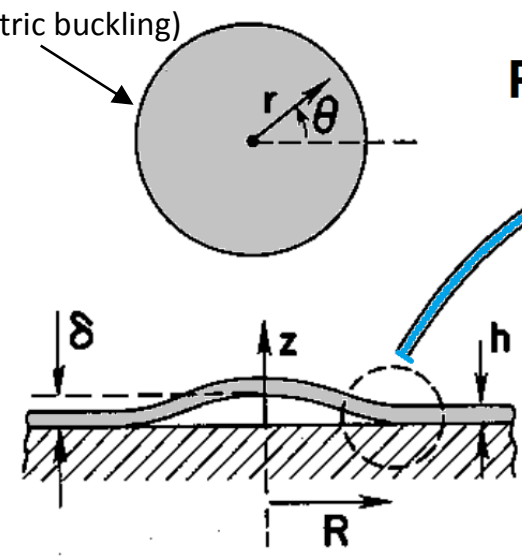

(a)
Bifurcation of circular buckle (non-axisymmetric buckling)

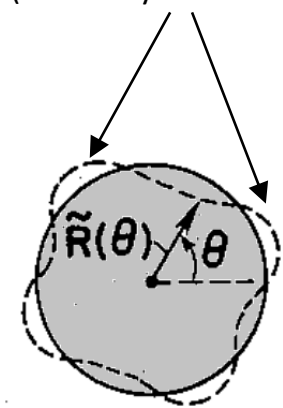

$\tilde{R}(\theta)=R(1+\epsilon \cos n \theta)$

(b)

Figure 7. (a) Convention for axisymmetric blister and plane strain problem at edge of the interface crack (b) Perturbation of the circular interface crack front [23]

The second possible source of non-axisymmetric behaviour considered is the instability to non-circular perturbations of the circular crack front. By considering the notation in fig. 7 (b), it is possible to write the perturbations in the crack front as, 


$$
\widetilde{\mathbf{R}}(\boldsymbol{\theta})=\mathbf{R}(\mathbf{1}+\boldsymbol{\epsilon} \cos \mathbf{n} \boldsymbol{\theta})
$$

Where, $\epsilon$ denoted the perturbation parameter. This type of configurational instability is noticeable in delaminations presented in [26]. This type of configurational instability accounts for the formation of telephonecord blisters, frequently observed in film delamination.

The comprehensive study of the stability of the crack front of the circular blister describing the lowest order of the perturbation in the strain energy release rate $G$ is defined in eq. 21 . The same equation can now be modified for perturbation analysis as,

$$
\mathbf{G}=\mathbf{G}_{\mathbf{o}}\left(\frac{\sigma}{\sigma_{\mathrm{c}}}\right)+\epsilon \mathbf{G}_{1}\left(\frac{\sigma}{\sigma_{\mathrm{c}}}, \mathbf{n}\right) \cos \mathbf{n} \boldsymbol{\theta}
$$

Where $G_{0}$ value of $G$ is the stable axisymmetric state while $G_{1}$ is the Fourier coefficient related to the lowest order perturbation. Together $\mathrm{G}$ and $\mathrm{G}_{\mathrm{o}}$ are governed by $\psi$ and the selection of elastic mismatch parameters along with the other governances specified. Stability relating to perturbation of the crack front for a specified $\mathrm{n}$ hinges is decided by the sign of $\mathrm{G}_{1}$. The condition for the propagation along the crack front is the increasingly stable trend of $\mathrm{G}$ along with $\sigma / \sigma_{\mathrm{c}}>1$. Therefore, if $\mathrm{G}_{1}$ is negative for a specified $\mathrm{n}$, then the perturbation is stable in the sense that the outward excursions of the crack front experience the lower G-value comparative to the innermost points along the front. This crack will continue its stable circular form during its expansion as shown in fig. 8. On the other hand, if $G_{1}$ is positive, the outward excursions experience the higher G-values and the perturbation is unstable. For positive $\mathrm{G}_{1}$, the crack will be driven further away from the circular shape during its expansion and ultimately may result in telephone cord like pattern.

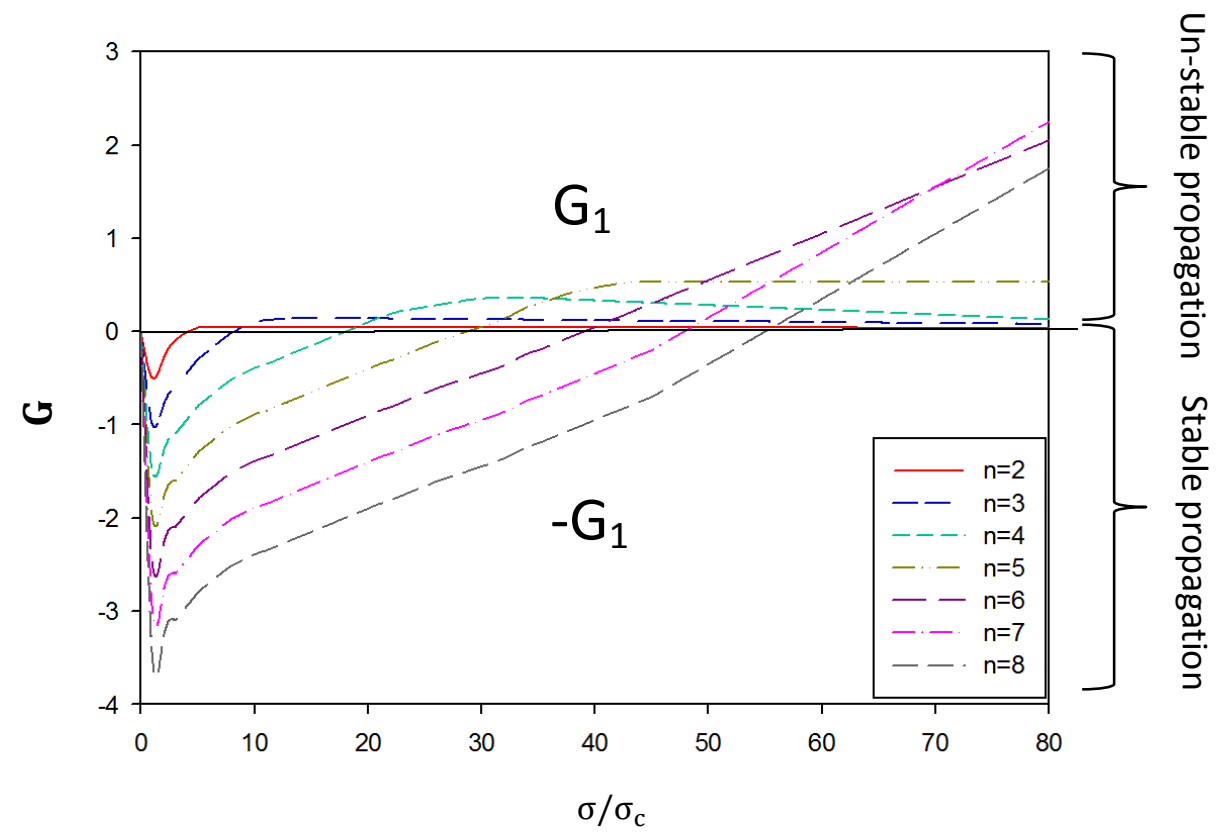

Figure 8 . The perturbation trends of $\mathrm{G} v \mathrm{vs} / \sigma_{\mathrm{c}}$ defining the stability and unstability of circular buckle delamination

\subsubsection{Types of interfacial cracking}

For the bi-material film-substrate system which is subjected to thermal expansion mismatch or other residual stresses, two types of major film failure modes are observed: i.e. 'buckle delamination' and 'edge delamination' as shown in fig. 9. The shapes and growth of the buckle delamination mode in films can lead to the development of interesting patterns such as telephone cord and network like blisters. 

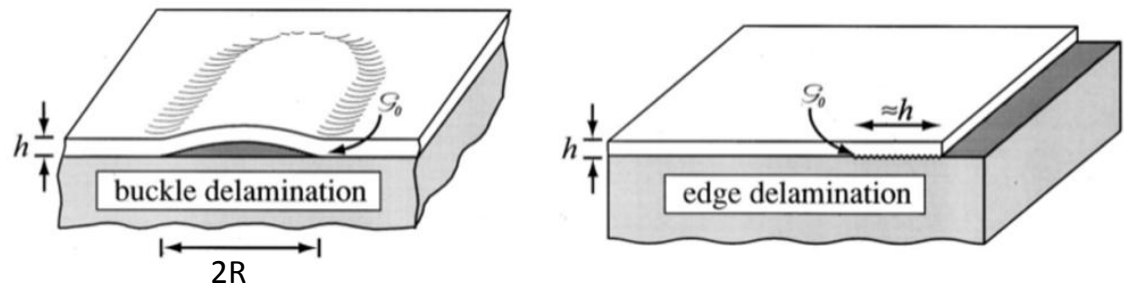

Figure 9. Types of interfacial cracking (towards left) buckle delamination and (towards right) edge delamination

\subsubsection{Buckle delamination}

Buckle delamination is commonly observed in compressed films bonded to elastic substrates. Buckle delamination results in the formation of interfacial crack and includes the concurrent propagation of buckling and interfacial decohesion. Buckle delamination evolves when the compressive stress in films exceeds the critical bonding strength of films with the substrate i.e. $\sigma / \sigma_{\mathrm{c}}>1$. This kind of delamination, after evolvement, propagates beneath the film in a stable pattern but becomes unstable after certain value of compressive stress is reached as discussed previously. Therefore, for buckle delamination, the condition of instability strongly depends on the elastic properties of film and substrate, in addition to interfacial bonding. Buckle delamination has many applications, such as calculating the adhesion energy, elastic modulus, residual stress and so on however they are not in the scope of this research and can be found elsewhere [27-31].

Various morphologies of buckle delamination exist for film substrate systems depending on the film thickness, the film stress, the film shape and the interfacial toughness between the film and the underneath substrate. These morphologies are straight side, circular, telephone cord and network like blisters [32] as shown in fig. 10. Among them, the most frequently observed morphologies are circular and telephone cord blisters. The telephone cord blisters normally evolve at film's edge due to unstability in circular or straight side blisters above a specific value of compressive stress in films. Furthermore, the telephone cord blisters can bifurcate and form a vast variety of buckling patterns such as parallel arrays or network-like shapes [33].

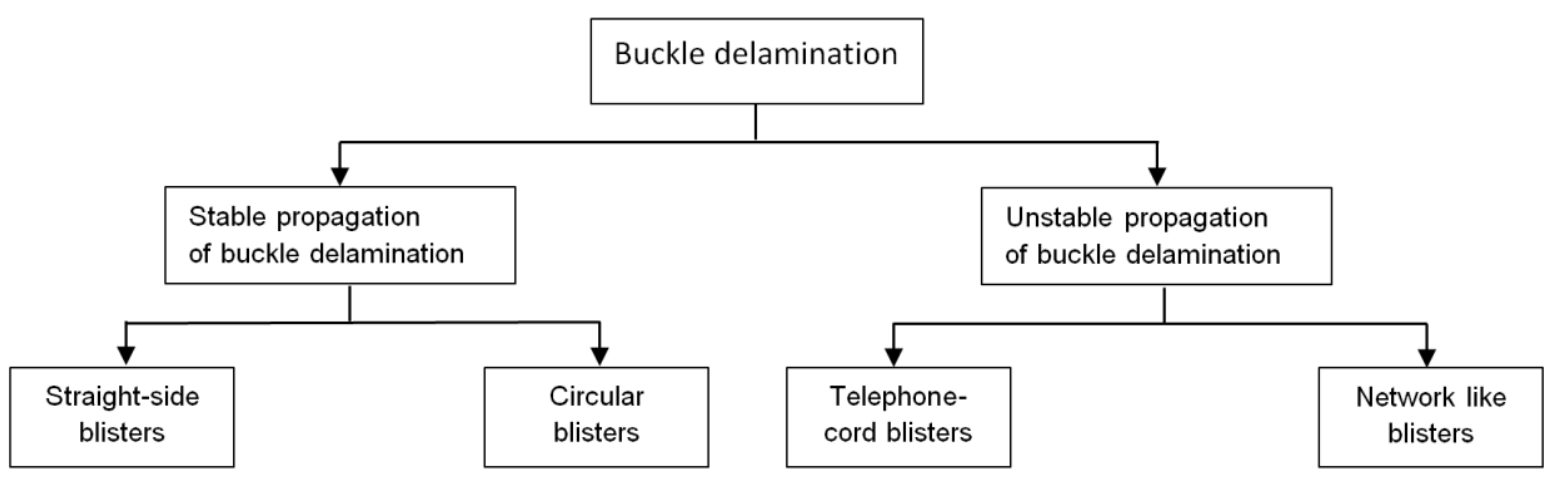

Figure 10. Flow chart for various morphologies of buckle delamination. Each morphology encompasses distinct modelling methods.

A number of authors have analysed film buckle delamination under the effects of equi-biaxial compressive stresses. These stresses may evolve due to thermal expansion mismatch (CTE) between film and substrate. The evolution of the blistering (straight-sided, circular, and telephone cord) due to compressive stresses as a result of CTE mismatch induces buckle delamination as shown in fig. 11 (a-c) respectively. Straight sided blisters propagate with a curved front which transform in to telephone cord blisters. The corresponding mechanics for telephone cord blisters are less well developed; some basic modelling concepts [34] and an advanced experimental analysis can be found in [35]. The conditions at the stationary side and the circular front of a propagating blister has been modelled and rationalized in terms of mode mixity and energy release rate $[22,36]$. 
Recently, much advanced model for blister propagation incorporating above equations (previous sections) have been developed in [37].
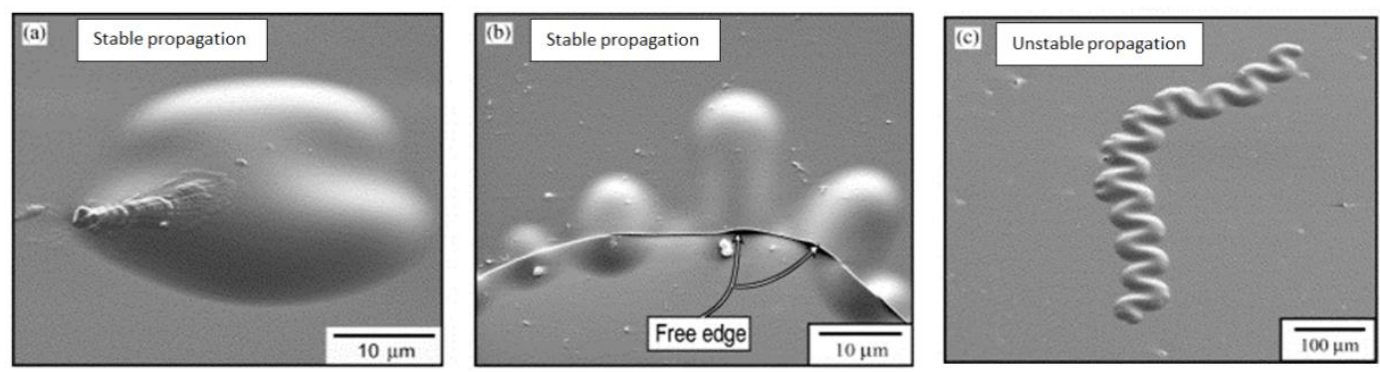

Figure 11. SEM images of (a) circular (b) straight-sided and (c) telephone cord blisters [38]

In the last two decades of previous centaury, Hutchinson and his colleagues (Thouless, Suo, He and Jensous) revolutionised the modelling for film buckle problem and developed several theoretical models to analyse the mechanism of buckle delamination.

Hutchinson et al [39] pioneered in the development of mechanics of the buckling delamination of compressed films by combining the concepts of fracture mechanics and post-buckling theory. They demonstrated that the buckling radius $2 \mathrm{R}$ of compressed film depends on the film stress $\sigma$ and film thickness $\mathrm{h}$, where the change in stress $\Delta \sigma$ is always positive.

The results for growth and stability of circular buckling investigated by using Föppl-Von Karman model showed that the unstable growth of circular blister results in telephone cord/ tunnel blister which can be modelled by using the concept of perturbation theory [23, 40] as shown in fig. 11 (c) and 14 (a). Later on, the frictional effects at the contact regions along the interface were incorporated based on the series of experiments [22, 23, $39,41]$. A comparison of the analysis with the experimental data indicates that in contact regions, the frictional stress which corresponds to the interface toughness is apparently high compared to yield shear strength. The constant frictional stress $\boldsymbol{\tau}$ acts between the crack surfaces with the contact region of length $\mathrm{d}$ and influences the dimensionless strain energy release rate $G_{\text {tip }} / G$ at the crack tip.

$$
\frac{G_{\text {tip }}}{G}=1-C\left(\frac{d}{h}\right) \frac{\tau}{P_{1}}
$$

Where $G_{\text {tip }}$ is the energy release rate at crack tip, $\mathrm{C}$ is the frictional coefficient, $\mathrm{d}$ is the length of contact zone behind the crack tip. For a wide range of delamination patters, the crack front progressively goes from mode I to mode II during blister propagation which also depends on the frictional stress $\boldsymbol{\tau}$, significantly deciding the severity of mode change [42].

The effects of prototypical imperfections (fig. 12) (wavy/wrinkle/undulation imperfections at the interface which account for the nucleation of separations at the interface of thermal barrier coatings) on the evolvement and propagation of buckle delamination in compressed thin films can be calculated by energy release rate as $[43,44]$,

$$
\frac{\mathbf{G}}{\mathrm{G}_{\mathrm{o}}}=3\left(\frac{4 \mathbf{k}}{3}\right)^{\frac{2}{3}} \text { where, } \mathbf{G}_{\mathrm{o}}=\frac{\left(1-\mathbf{v}^{2}\right) \mathbf{h} \sigma_{0}^{2}}{2 \mathrm{E}}
$$

and

$$
k=8 \int_{0}^{L / 2}\left(\frac{\delta}{h}\right) \cos \left(\frac{2 \pi x}{R}\right) d x
$$




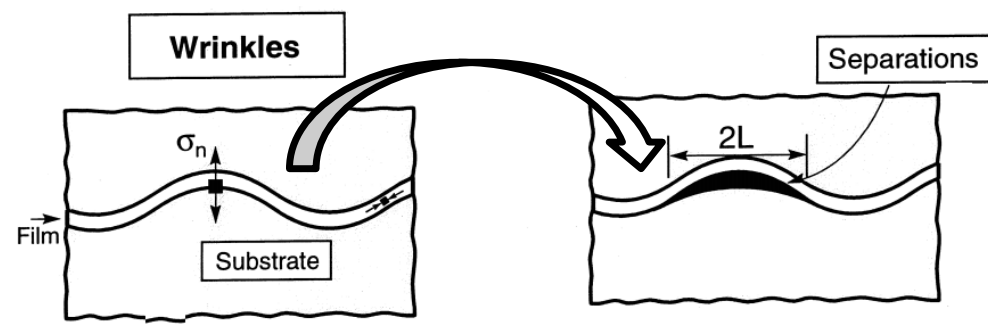

Figure 12. Imperfections that create a separation at the interface of the dense ceramic layer (normally $\mathrm{Al}_{2} \mathrm{O}_{3}$ ) and the metallic bond films in multilayer systems [43]

Where, $G_{o}$ is the energy per unit area stored in the unbuckled film. Since k is directly related to the imperfection amplitude $\delta$, eq. 31 dictates that, for the case of very small imperfections, the energy release rate becomes $G \approx$ $\delta^{\frac{2}{3}}$. The power law $2 / 3$ amplifies the influence of small imperfections, creating an extraordinarily large rise in G. The criterion (critical imperfection wavelength $L_{o}^{c}$ ) are identified for the propagation initiation which can be used to control buckling.

$$
\mathbf{L}_{\mathbf{o}}^{\mathbf{c}} \approx \mathbf{1 1}\left(\frac{\overline{\mathrm{E}}_{1} \Gamma_{\mathrm{i}}}{\sigma_{\mathrm{c}}^{2}}\right) \sqrt{\frac{\overline{\mathrm{E}}_{1}}{\sigma_{\mathrm{c}}}} \text { where } \Gamma_{\mathbf{i}}=\mathbf{G}
$$

$\Gamma_{\mathrm{i}}=\mathrm{G}$ is the incipient condition for imperfection spread and $\Gamma_{\mathrm{i}}$ is the mode I toughness.

The curvature of substrates plays a vital role in buckling. For curved substrates, the energy release rate of modal stress at the crack edge strongly depends on the curvature of substrate. Circumferential propagations is reduced for negative curvatures and is accelerated for positive curvatures as shown in fig. 13 [36]. The average steadystate energy release rate, G, along the curved front of a straight sided, circumferentially propagating blister is evaluated by computing the difference in the elastic energy in the film well ahead of the blister front and that well behind (refer to eq. 13). The outcome of this computation is,

$$
\frac{\mathrm{G}}{\mathrm{G}_{\mathrm{o}}}=1-(\mathrm{CP})^{2}+\frac{2 \mathrm{E}_{1}}{\left(1-\mathrm{v}^{2}\right) \sigma_{\mathrm{c}}^{2} \mathrm{~h} 2 \mathrm{R}} \int_{0}^{\mathrm{R}} \frac{(1-\mathrm{v}) \sigma_{\mathrm{c}} \delta}{\mathrm{R}}-\frac{\mathrm{E}_{1} \mathrm{~h}\left(\frac{\delta}{\mathrm{R}}\right)^{2}}{2}-\frac{\mathrm{D} \delta^{\prime \prime 2}}{2} \mathrm{dx}
$$

Where $\mathrm{CP}$ is the term defining the curvature properties of substrate, detailed derivations for $\mathrm{CP}$ can be found in [36]. $G / G_{o}$ depends on $C P, E_{1}, R, h, \sigma_{c}, D$ and $\delta$. D is the flexural rigidity (bending stiffness) of film i.e. $D=\frac{E_{1} h^{3}}{\left[12\left(1-v_{1}^{2}\right)\right]}$
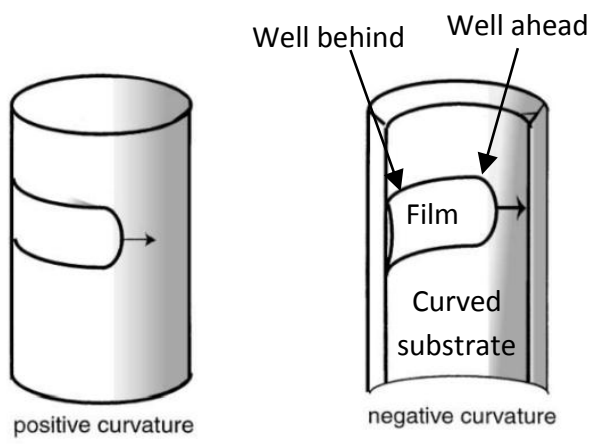

CIRCUMFERENTIAL PROPAGATION

Figure 13. Straight-sided blisters propagation of curved substrate [36]

Elastic deformation of substrate can significantly affect the buckle initiation [45]. The energy release rate at the crack edge incorporating the elasticity of substrate can be several time higher than the one derived using 
conventional equations of simple film debonding without inclusion of substrate elasticity. The buckling propagation rate reduces with the increase in substrate's elasticity [46]

The propagating blister becomes unstable and starts to undulate forming a network for high strains beyond the threshold strain i.e. $G>G_{c}$ as shown in fig. 14 (b) [47]. Above the threshold strain $G_{c}$ and under high residual stress, the telephone cord blisters are dominant in number compared to circular or straight side blisters which are generally narrower, if they exist under high stresses [48]. Furthermore, for a compressed film, if the buckle has nucleated and threshold has been crossed then various morphologies (from simple telephone cord to complex telephone cord) are formed as shown in fig. 14 (c) [49]. It has been shown [50] that the stability range between straight side and telephone cord blister shows a smooth transition.

For the unstable blister with strain beyond the threshold point, if the substrate is as stiff as film i.e. $\mathrm{E}_{1}=\mathrm{E}_{\mathrm{s}}$, then the energy of the substrate significantly accelerates the unstable buckle propagation under compression by contributing to energy release rate [51]. The possible reason for telephone cord blisters in such case is the increase in mode mixity $\boldsymbol{\Psi}$ with the propagating telephone cord tunnel.

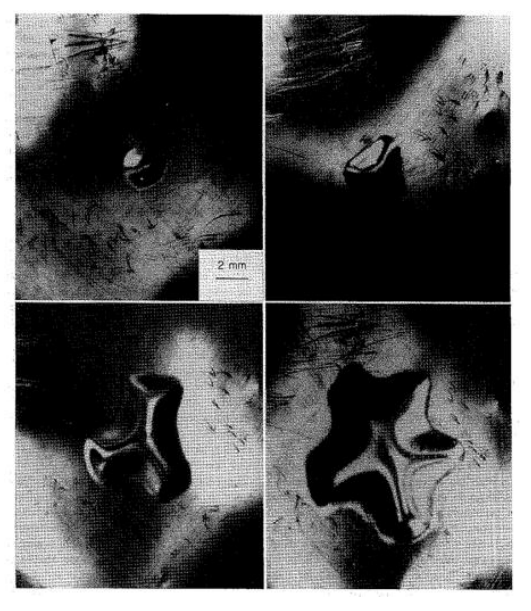

(a)

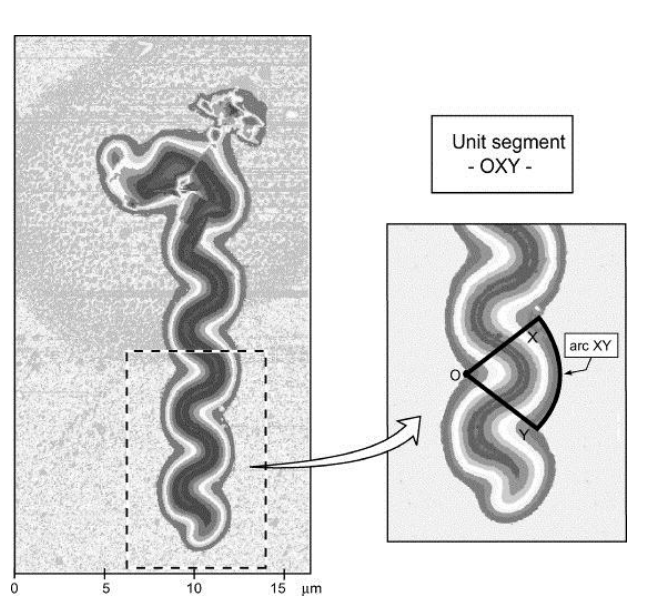

(b)

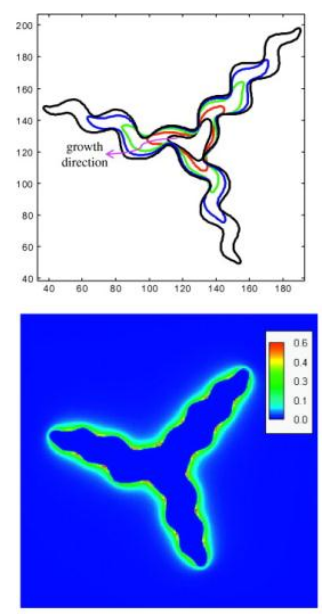

(c)

Figure 14. (a) SEM images of blister transitioning from stable circular pattern to non-axisymmetric unstable telephone cord pattern [23] (b) Telephone cord blister highlighting the unit segment with centre of curvature at $\mathrm{O}$ and length of arc at XY [48] (c) The influence of mixed-mode conditions on the evolvement of telephone cord blistering morphology [46, 49].

\subsubsection{Indentation - induced interior edge delamination}

Unlike buckle delamination, edge delamination due to indentation occurs without buckling. The indentationinduced edge crack problems share the same equations for that buckling in terms energy release rate and mode mix conditions [52], however the only difference is that the edge delamination is the result of mechanically induced defect through indentation. For the case of indentation-induced interior edge problem, a straightforward situation is discussed as shown in fig. 15 [39]. The analysis assumed the complete plastic deformation of film just beneath the contact point, producing a uniform compressive equi-biaxial stress in the film nearby the zone of plastically deformed film. Considering the delaminating film as a clamped disk under compressive stress, the critical load responsible for film buckling or delamination was predicted. For the film which is indented, consequently producing buckling at the interior edge along the interface, a post buckling examination was utilised to evaluate the loads at the edge of film (see fig. 15) responsible for delamination propagation. In addition to this, a strain energy analysis (identical to the one reviewed previously), helped in the development of the expressions for mode mix and strain energy release rate for indentation-induced interior edge buckling. It is worth noting that even if the buckling does not occur, still, the delamination can be propagated under the compressive load having a phase angle equivalent to $\omega$ (eq. 23 with $\mathrm{M}_{1}=0$ ), depending on the elastic parameters $\alpha$ and $\beta$, and can be consulted from table in reference [53] 


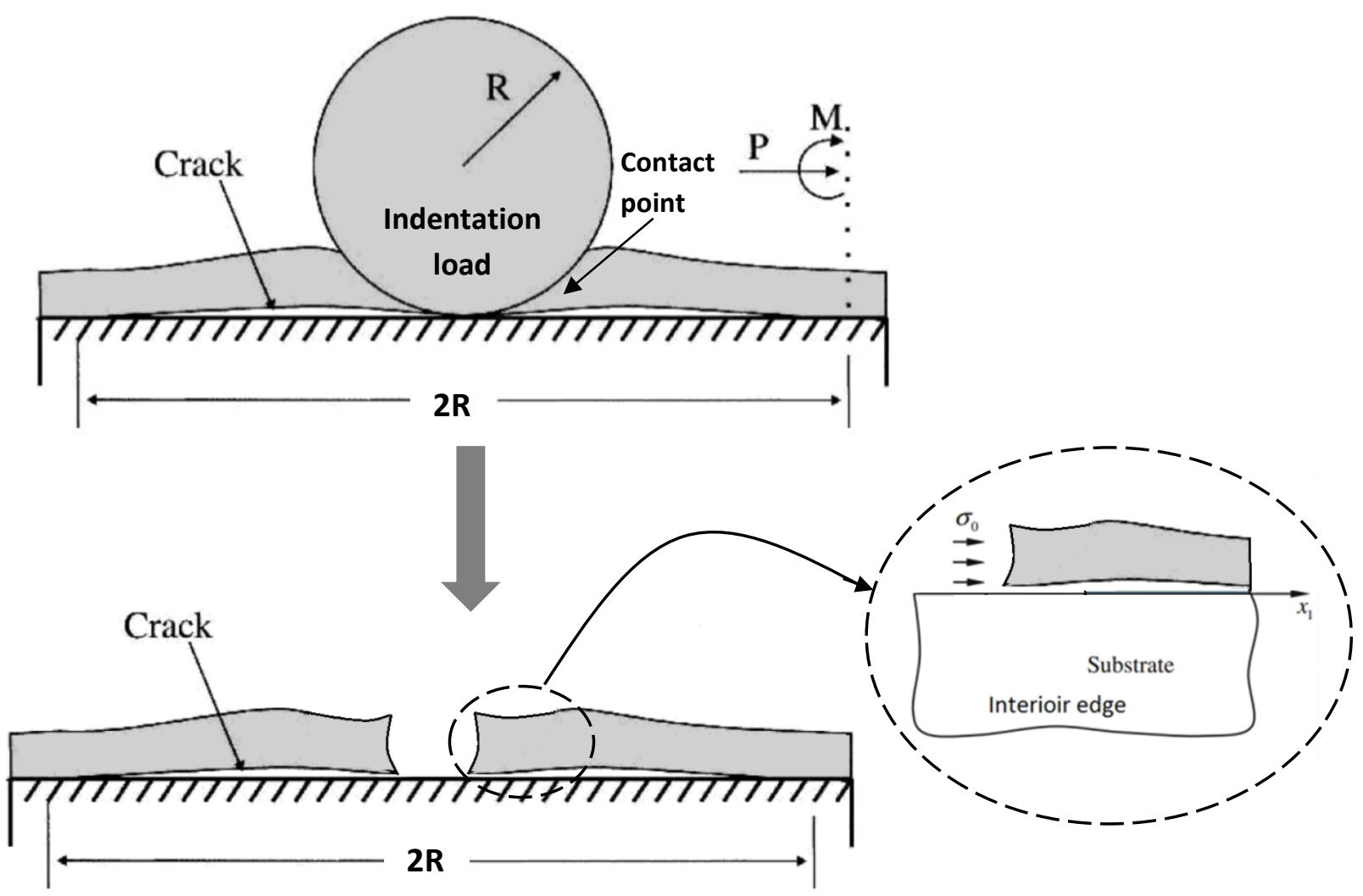

Figure 15. Indentation-induced interior edge buckling delamination of a film. Corresponding edge loading on thin film is also shown [53]

The above approach was modified for the analysis of indentation-induced delamination of a compressed thin film involving mode II interface cracking under the combined frictional stresses and roughness effects [54]. The model assessed the possibility to explain the large mode II fracture toughness with the frictional shielding and interfacial roughness effects. Later on, the effects of both $\mathrm{T}$ stress and mode mixity on the interfacial cracking were analysed [55].

The indentation-induced delamination modelling of non-isotropic (or orthotropic) bi-materials is a complex problem [56] because it includes many material constants which make the numerical solution for interior edge delamination more complex and difficult to present in a compact form. Not much models exist addressing edge delamination problem for orthotropic materials. An example of one such model is [56] which analysed the interior edge crack in an orthotropic bi layer strip. Later, the influences of delaminations evolving at the edge/corner of film-substrate system considering orthotropic bi layer strip was analysed in [57, 58] however, these models were limited to homogeneous layers.

Indentation is also used for extracting the mechanical properties in addition to analysing the deformation mechanisms of films. This is normally performed by using nano-indentation load-displacement curves. Some papers address the experimental [59] and modelling simulation [60] techniques of nano-indentation of films and perform a comparative study with the testing of bulk materials.

\subsection{Other cracking patterns}

The above analysis only considers the interfacial fracture however numerous other cracking patterns in film systems under the effect of residual stresses, are also widely examined. Most common patterns include: film surface cracks (fig. 16), film channelling cracks (fig. 17), substrate cracking (fig. 18) and spalling (fig. 19). A detailed review of these patterns can be found in [61] and is summarised here. 


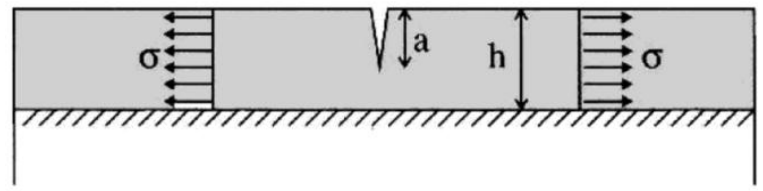

Figure 16. Surface cracking of film due to tensile residual stress [61]

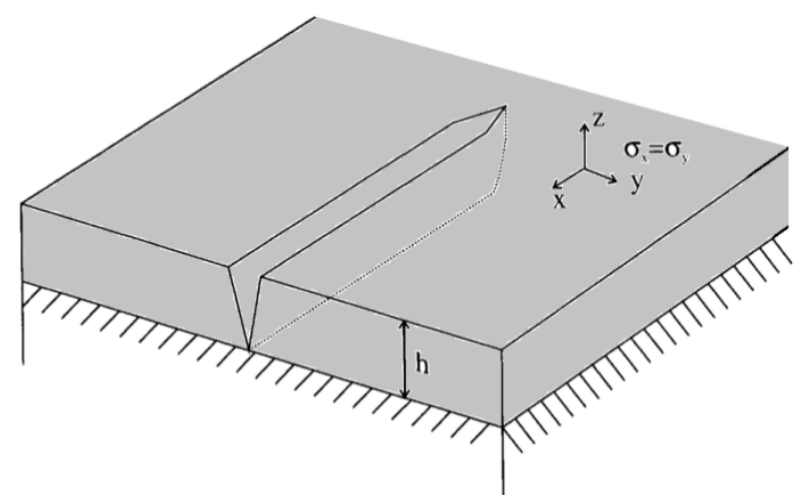

Figure 17. Crack channelling in the film under the effect of tensile residual stress [25]

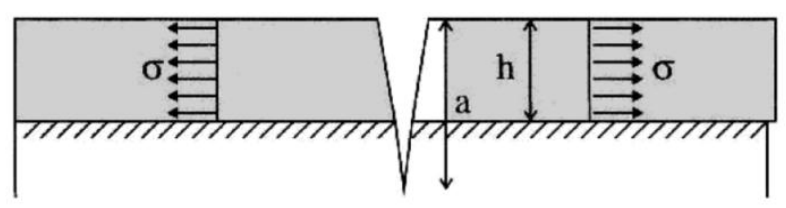

Figure 18. Crack with its tip in the substrate under the effect of tensile residual stress [61]

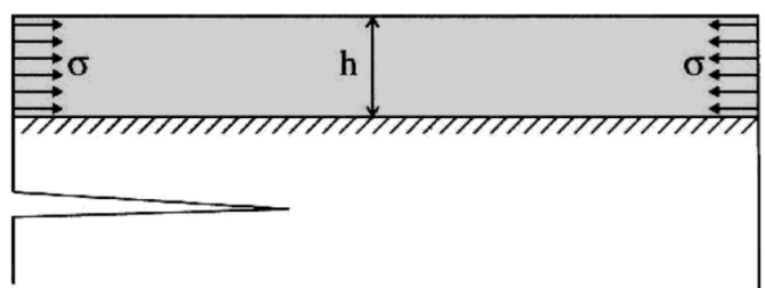

Figure 19. Substrate spalling as a result of compressive residual stress in the film [25]

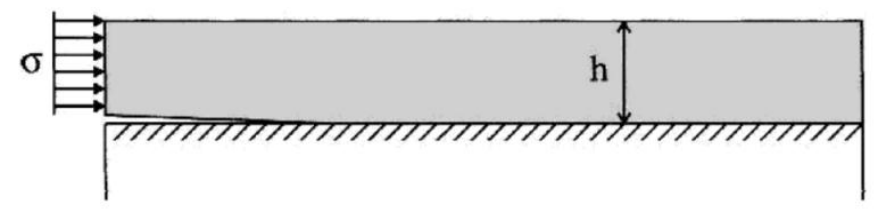

Figure 20. Crack emerging from the edge or hole forming edge crack which then starts propagating along the film-substrate interface [61]

Confining ourselves to the condition when the film is significantly thinner compared to the substrate, following observations are made for cracking patterns which are likely to evolve. The mode mix and energy release rate for all cracking patterns (fig. 16 to 19) are affected by the film thickness, the fracture toughness of the interface, film and the substrate, and elastic properties of the film and substrate [62]. This section will analyse the relative likelihood of the propagating crack with a specific pattern depending on the above parameters. 
It was shown in [24, 63], that irrespective of the case whether the cracking evolves along the interface, in the film or in the substrate, the strain energy responsible for driving the crack propagation under the influence of a residual stress $\sigma$ is related as,

$$
\mathbf{G}=\frac{\mathbf{A \sigma ^ { 2 }} \mathbf{h}}{\overline{\mathbf{E}_{\mathbf{c}}}}
$$

Where, $\mathrm{h}$ is film thickness, $\overline{\mathrm{E}_{\mathrm{c}}}$ (previously $\overline{\mathrm{E}_{1}}$ ) is expressed in eq. 10 and, the dimensionless integer $\mathrm{A}$ is governed by the geometry of cracking pattern in addition to the elastic properties of the film and the substrate. For a specific cracking pattern if the film is significantly compliant and thicker compared to the substrate then there is likelihood for the cracking to propagate. And this seems possible, as from eq. 35, the strain energy release rate in the film rises with increasing film compliance and thickness. During the crack propagation, $G=$ $\mathrm{G}_{\mathrm{c}}$, the relevant fracture toughness is a function of the case that whether the crack is along the interface, in the film or in the substrate. Therefore to predict the critical film thickness $h_{c}$, under which the propagation of crack do not initiate, eq. 35 can be utilised as [63]

$$
\mathbf{h}_{\mathbf{c}}=\frac{\mathbf{G}_{\mathbf{c}} \overline{\mathbf{E}_{\mathbf{c}}}}{A \boldsymbol{\sigma}^{2}}
$$

Cracks which propagate in the film or in the substrate normally follow the criterion $\mathrm{G}=\mathrm{G}_{\mathrm{Ic}}$ and propagate along path of maximum mode I. On the other hand, as analysed in the previous sections, if the crack propagates along the interface, then $G_{c}$ (eq. 36) should be selected by the appropriate phase angle for the specific geometry and loading [64].

Different values of A corresponding to various cracking patterns with the assumption of zero elastic mismatch between film and substrate were evaluated in [65]. The results showed that the highest A takes place for surface crack in a film while the lowest A takes place for substrate spalling. However, such results surely do not guarantee the fact that film is always most likely to face surface cracks compared to substrate spalling, as there are some other parameters that also decide patterning such as: the presence of a defect in the film or the substrate (the A values, mentioned correspond to the steady state propagation in the company of already existing defect, and do not consider the nucleation of crack), relative fracture toughness of the film and substrate.

Table 1 summarises the reliance of A values on the elastic properties of the film and substrate corresponding to various cracking patterns which have not been covered previously, accompanied with the appropriate articles necessary for further understanding. For Table 1, following considerations were taken in to account: (a) for a thin film on a substrate i.e. $\eta=0$, the trends have been extrapolated; (b) as A is governed by $\beta$, therefore, an equivalent approximate representation of $\beta=\alpha / 4$ is considered, specific for condition when Poisson's ratio of both film and substrate are same; (c) interfacial cracking is based on mixed mode criterion, so reliance of the phase angle in terms of relevant fracture toughness is also shown and (d) wherever possible, trends of $E_{s} / E_{c}$ approached zero and infinity, are presented.

Table 1 presents, just the steady state values for already existing cracking geometry, assumed before. As discussed previously, that the appearance of a specific cracking significantly relies on the mix mode (since $G_{\text {IIc }}$ is normally larger than $\mathrm{G}_{\mathrm{Ic}}$ ), the relative fracture toughness of interface, substrate, and the film. For the case of relatively brittle substrate, cracking is more likely to occur, as it depends on $\mathrm{G}_{\mathrm{Ic}}$ in homogenous materials. Now we will proceed with the discussion of Table 1 .

Table 1. Summary for various values of A for thin films [25, 61]

\begin{tabular}{|c|c|c|c|}
\hline \multicolumn{1}{|c|}{ Cracking pattern } & Dependence of A on $\mathbf{E}_{\mathbf{s}} / \mathbf{E}_{\mathbf{c}}$ & $\begin{array}{c}\text { Relevant fracture } \\
\text { toughness }\end{array}$ & References \\
\hline $\begin{array}{l}\text { Surface cracking in film } \\
\text { (fig. 16) }\end{array}$ & $E_{s} / E_{c}=0.11\left\{\begin{array}{lll}A \rightarrow \infty & \text { for } & \frac{a}{h} \rightarrow 1 \\
A=3 & \text { for } & \frac{a}{h}=0.5 \\
A \rightarrow 0 & \text { for } & \begin{array}{l}a \\
h\end{array} \rightarrow 0\end{array}\right.$ & Film mode I \\
\hline
\end{tabular}




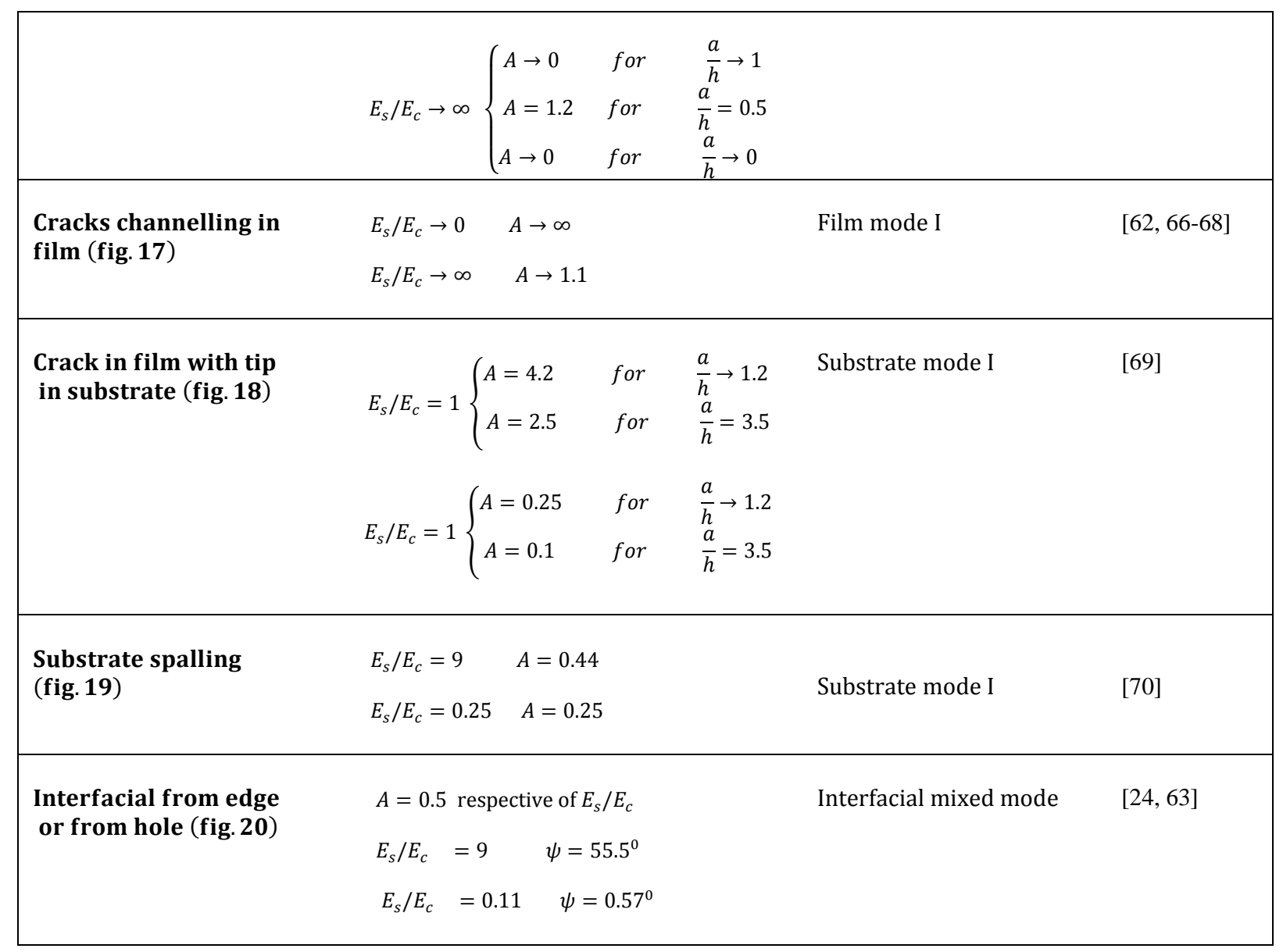

\subsubsection{Surface cracking and crack channelling in film}

The coating stiffness is represented as $\overline{\mathrm{E}_{\mathrm{c}}}$ and exists in denominator in eq. 35, meaning that, as stated previously, it is more likely for any type of cracking to occur in compliant films compared to stiff films [68]. However, the value of $A$ is governed by the ratio of film stiffness to substrate stiffness $E_{s} / E_{c}$, and some vital observations are made from the data in Table 1. For film surface cracks, if film is significantly stiffer than substrate, then Table 1 reveals that the crack driving force rises on the crack's approach at the interface, such that the crack will continue propagating in to the brittle substrate [66]. Conversely, if substrate is significantly stiffer than film, the opposite is likely to happen, such that the crack is expected to arrest at the interface [71]. If both the film and substrate are relatively tough, and the film is significantly stiffer compared to substrate, then the surface crack is more likely to channel across the film's surface as shown in table 1, where the crack driving force is high for channelling, in the case of a stiffer film than the substrate [72].

The density of surface cracks in film and minimum spacing ' $l$ ' that exist between a series of parallel propagating cracks as shown in fig. 21 depends on the specific thickness limit $[73,74]$. For the propagating cracks, once the critical condition $h_{c}$ (eq. 36) of propagation has been met, the crack density will increase with the increasing film thickness and the stress $\sigma$. The reduced density of the cracks is possible to be attained, if the initial concentration of the suitable defects is sufficiently large. However, if the density of initial defects is very low, the spacing between the cracks will be modelled by using 'initial defect distribution' as discussed here in [73]. Another observation is that the crack driving force decreases with the increase in crack density [75]. Under plane strain conditions, the energy-release rate at the tip of each crack is given by,

$$
G=\frac{\sigma^{2} \pi z\left(1-v_{c}^{2}\right)}{E_{c}} F(s)^{2}, \quad F(s) \begin{cases}=1.12 & \text { for } 0 \leq s \leq 0.2 \\ =\sqrt{\frac{1-s}{\pi s}} & \text { for } 0.2 \leq s \leq 1\end{cases}
$$


where $\mathrm{s}$ is $\frac{2 z}{l+2 z}$ and $\mathrm{F}(\mathrm{s})$ is a function that depends only on crack depth $\mathrm{z}$ and spacing $l$.

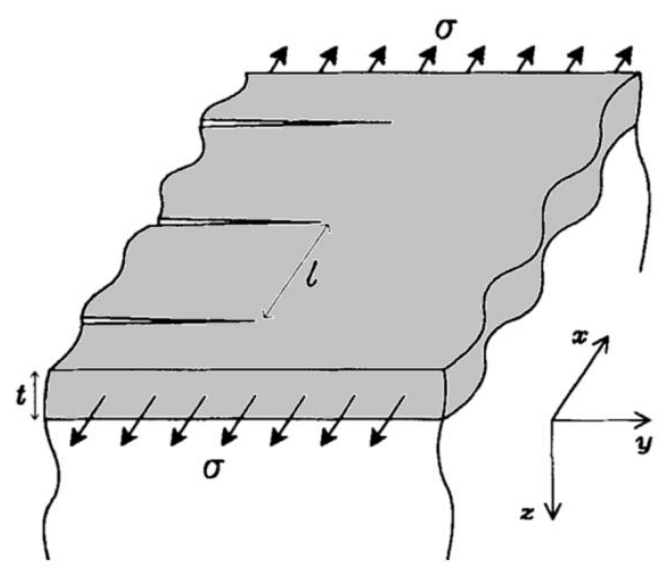

Figure 21. Schematic of propagating cracks with crack spacing ' $l$ ' in a thin elastic film bonded to the substrate [73]

For the case of multiple cracks, when the spacing between the cracks is not large enough, the stress intensity factor (eq. 18) at the edge of cracks is very high [76]. This effect becomes stronger for the case of relatively stiffer films compared to the substrate [77]. Stiffer films account for larger crack spacing for a given mismatch stress. Crack nucleation is considered to be easy for the stiffer films compared to the compliant films. For compliant films, both crack nucleation and crack density are higher for large elastic mismatch values.

The results for the effects of substrate thickness on film cracking show that the thickness of the substrate significantly effects the steady state energy release rate of crack propagation [78]. The crack propagation is also a function of the boundary conditions of the substrate. For the case when the substrate is clamped around the edge, the crack driving force significantly increases with the increase in substrate's thickness. The reason for the increase in crack driving force is because the incipient residual stress in the film cannot relax which results in high crack driving force. However, for the case when the substrate relaxes on release, the stresses in the films relax back and the crack driving force is decreased.

Recently, a model [79, 80], is developed which utilises a novel extended finite element method (XFEM) to simulate the steady-state energy release rate of cracks propagating thorough stressed film in the form of channelling. In the XFEM, special functions are added to the existing finite element approximations by using the framework of partition of unity. XFEM technique has been further utilised to simulate the two dimensional cracking in isotropic media by using the discontinuous function and the two dimensional asymptotic crack displacement fields [80].

Many papers describe the stress distribution in film before cracking under loading in experimental and modelling simulation. However, this section only focuses on post cracking stress analysis while pre cracking stress distribution in film can be found elsewhere [81-84].

\subsubsection{Crack in film with tip in substrate and spalling}

Brittle substrate has a high possibility for a film crack to have the tip in substrate. Table 1 shows that for the case of films which are much stiffer compared to the substrate, the probability is high for the crack to continue propagating in the substrate parallel to the interface. It is clear from Table 1 that irrespective of the relative stiffness of the film and substrate, the increase in crack length results in the decease of crack driving force such that the crack is likely to propagate in a stable fashion, till a point where it may divert, becoming parallel to the interface i.e. spalling. The relative stiffness of the film and substrate do not influence the possibility of such happening as evident from Table 1. It is worth noting that, for a specific case, when the load induces the crack closure then spalling is least likely to happen under the tensile edge loads (i.e. compressive residual stress). Detailed experimental studies have been performed for cracks propagating in the film and extending from the surface of film to the film-substrate interface [85] and furthermore penetrating into the substrate $[85,86]$. 
For interfacial cracks, the ratio of substrate stiffness to thin film stiffness $E_{s} / E_{c}$ does influence the crack driving force (eq.37) however it does increase with increasing the film's compliance. For a given mixed mode, the mode II component directly influences the fracture toughness of interfaces, which means that the probability of interfacial crack to propagate is high when the substrate is significantly stiffer compared to the film. For the case of compressive residual stress in film, the tensile end condition may affect the layer, which may result in the crack closure therefore, it is important to consider the crack face friction, similar to eq. 30 [63].

The propagation of crack in the substrate or along the interface is influenced by channel cross-section (which is governed by the fracture properties of the interface and the substrate), film thickness, residual stress and Young's moduli [69]. The critical film thickness which is required to avoid cracking failure is found to be lower if the crack penetrates in to the substrate compared to crack which propagates along the interface [69].

There is a specific film to substrate critical stiffness ratio, beyond which the stability of propagating crack corresponding to the applied load reduces [87]. There is a regime below the critical ratio, which accounts for the stable propagation of cracks. For such regime, the increase in the depth of crack with the increase in strain results in the reduction of crack spacing. Eventually, the propagating crack may become deep enough so that it can penetrate in to the substrate causing the substrate to fail.

Some other complex cracking patterns for example spiral cracks are reported, and the paper [68] summaries a theory in terms of the incorporated effects of various cracking patterns described here, which seem to be able to predict more complex cracking patterns.

\subsection{Analysis for the case 'no pre-exiting interfacial crack exist'- Free edge singularity problem}

The previous analyses cover some important mechanisms of the interfacial fracture mechanics which describe the steady state propagation of crack, but does not include the interfacial crack nucleation/ or initiation. One major approach is based on the analysis of the free edge loading of a top layer and its corresponding stress field $[88,89]$. As it is assumed that the crack is not present initially, therefore prediction gives quite distinct singular field value, which can then be utilised to predict nucleation of cracks in stressed coatings. As the predictions from this case, often, contradict the predictions from the analyses in previous sections, therefore, this case has been discussed in a separate section.

For the case of bi-layer material, the interfacial stress near the edge show singularity response [90, 91]. To address this, many researchers have established advanced theories to examine the corresponding singularity behaviour for various edge orientations under different mechanical and thermal loadings [92, 93]. The papers $[88,89]$ have utilised this technique to examine the corresponding stress intensity in the vicinity of the free edge in a bi-layered system having the top layer loaded with a uniform stress evolving due to the thermal expansion mismatch (fig. 3, consider with no interfacial crack, thus $\left(P_{3}=P_{2}=M_{2}=M_{1}=0\right.$, only making $\left.P_{1}=\sigma h\right)$.

The interface stresses evaluated from free edge solution is given as [89],

$$
\begin{aligned}
& \sigma_{\theta, \theta}^{f e}=K_{f e} r^{\lambda-1}+\sigma_{0} \\
& \sigma_{r, \theta}^{f e}=K_{f e} r^{\lambda-1}+f_{r, \theta}(\theta=0)
\end{aligned}
$$

Where, $\sigma_{\theta, \theta}^{f e}$ is the normal interfacial free edge stress, $\sigma_{r, \theta}^{f e}$ is the shear interfacial free edge stress, and $K_{f e}$ represents the stress intensity factor near free edge and is given as,

$$
K_{f e}=\lim _{r=0} \frac{\sigma_{\theta, \theta}^{f e}(\theta)}{r^{\lambda-1}}
$$

Where $\lambda$ and $\theta$ depend on Dandur's mismatch $\alpha$ and $\beta$, and can be calculated empirically, as given in [89].

$\sigma_{0}$ can be written as, 


$$
\sigma_{0}=-\frac{\sigma}{\overline{E_{1}}}\left[\frac{8 \mu_{1} \mu_{2}}{\mu_{1}\left(k_{1}-3\right)-\mu_{2}\left(k_{1}-3\right)}\right]
$$

The subscripts ' 1 ' and ' 2 ' refer to the upper and lower layers of bi-material system respectively. The comparative analysis of eq. 38, 39 and eq. 4 reveals that the solution for steady state crack propagation is very different from the singularity free edge problem. Furthermore, the parameter $\lambda$, for $\beta=0$, shows full dependence on the material properties for the case of free-edge problem while it is always in the power of under root for the cases of steady state problem. Moreover, only one stress intensity factor affects the interfacial stresses for the case of free-edge problem while for the case of steady state, two stress intensity factors influence the interfacial stresses. In the paper [89], the steady state was compared with the free edge problem of [22, 24] and it was found that the free edge singularity showed significantly different behaviour in many terms.

For the case, when $\alpha$ is positive, the corresponding stress intensity factor $K_{f e}$ is negative, which means that the normal interfacial free edge stress of compressive regime exists when $\alpha$ is positive (eq. 38). Therefore, it is quite clear that when $K_{f e}$ is negative, the crack closure for both the steady state and free edge problem suggests the criterion to avoid crack propagation (steady state) and crack initiation (free edge). One important point that should be noted, from previous section, is that the negative $K_{1}$ is not desirable in case of steady state problems, because of the contact and the frictional complexities. However, from design point of view, negative $K_{1}$ benefits in crack closure, which reduces the risk of crack propagation and initiation because of the limited crack opening.

Fig. 22 shows the trend for $\boldsymbol{\eta}$ as a function of $\alpha$ keeping $\boldsymbol{\beta}=0$. It can be seen that there is a boundary inbetween the positive and negative $K_{f e}$ at $\alpha=0$. The normalised form of stress intensity factor for both the free edge and steady state can be written as,

$$
\begin{aligned}
& \mathbf{K}_{\mathbf{1}}^{*}=\frac{\mathbf{K}_{\mathbf{1}}}{\boldsymbol{\sigma} \sqrt{\mathbf{h}+\mathbf{H}}} \quad(\text { Steady state stress intensity factor }) \\
& \mathbf{K}^{*}=\frac{\mathbf{K}_{\mathbf{f e}}(\mathbf{h}+\mathbf{H})^{\lambda-1}}{\boldsymbol{\sigma}} \quad \text { (Free-edge stress intensity factor) }
\end{aligned}
$$

Where $\sigma$ refers to the applied loading stress on the upper layer. If the developed system is such that it exists in region $I$, then the system will be resistant to both the crack initiation and propagation (excellent design). The films are relatively extremely thin compared to substrate therefore $\boldsymbol{\eta}$ is small, which puts them in region III. However the improvement in the design of such films can be made by using significantly stiffer film or relatively much compliant substrate, making $\alpha$ small, and putting the film system in region IV, where somewhat crack initiation can be reduced. For complaint substrate bonded to multi-layered film, similar behaviour is observed which has been modelled in [94].

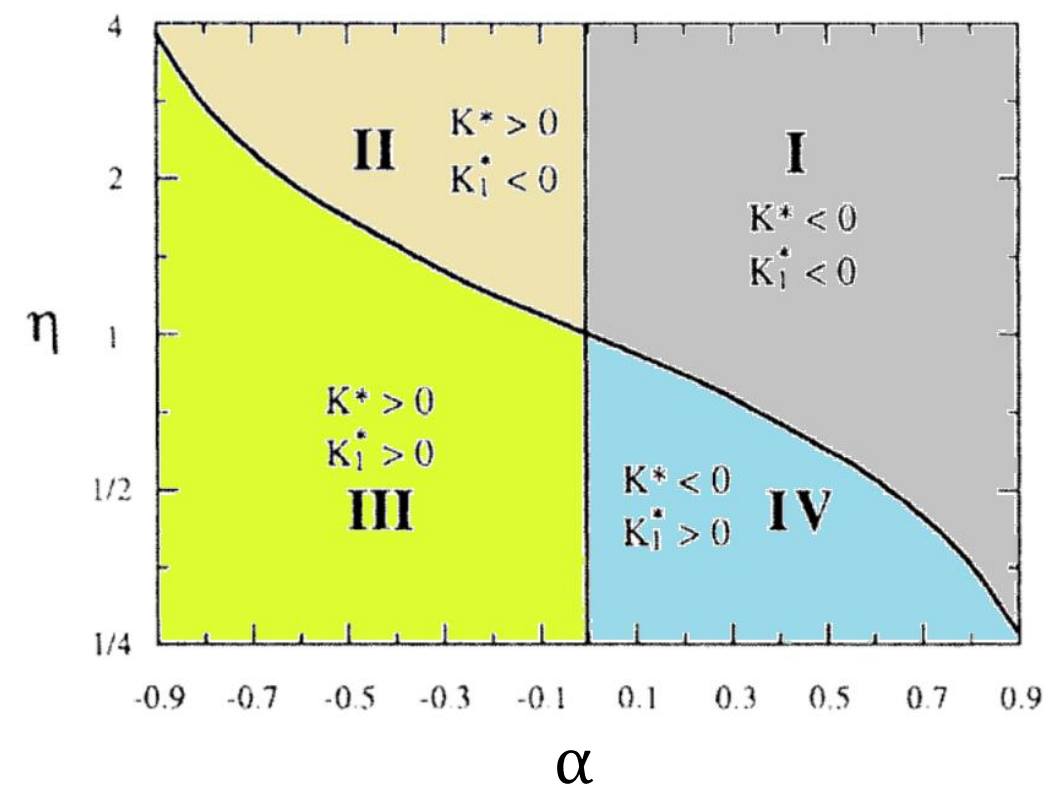


Figure 22. The trend for $\boldsymbol{\eta}$ as a function of $\alpha$ keeping $\boldsymbol{\beta}=0$ useful for film designing [89]

\subsection{Future scientific challenges in cracking modelling}

Cracks in films are mostly caused by residual stresses or mechanical loading. For crack channelling along the film, the driving force depends on the channel cross-section, as governed by the fracture properties of the interface and the substrate, in addition to known effects of film thickness, residual stress and elastic moduli. The crack propagating in film, depending on fracture properties may either divert towards the interface or substrate or it may continue propagating along the surface of film. In recent years, various theoretical models have been developed for all of the above cases by using more or less the same fracture mechanics concepts by Hutchinson [22-24, 36, 41, 43, 44]. After detailed literature survey, we suggest the following five improvements in existing cracking models of films.

- Non-linearities in blister propagation: From a fundamental point of view, the propagation of blisters indeed raises challenging issues because it results from the interaction of two complex phenomena: the out-of plane buckling of the blister (geometrical non-linearities) and the fracture-like process of rebounding. The non-linear propagation of blister resulting in tunnel like blister is a big challenge. Many researchers have modelled non-linear behaviour of blisters such as Hutchinson [23], however, the tunnelling behaviour is still not yet clear and requires detailed experimental study through AFM or SEM techniques, for improved models.

- Coulomb friction: The effect of friction stress in the contact zone of film and substrate under compressive loading across debonding interface is an important factor which can significantly influence the delamination rate. In interfacial debonding models, no attempt was made to compute the dependence of crack driving force on friction stress for a coulomb friction zone and an alternative to the coulomb friction was sought (e.g. [22, 23, 39, 41, 42, 54]). The incorporation of friction stress component in existing debonding models can produce results much closer to the experimental finding.

- Film cracking induced interfacial delamination: Interfacial delamination caused by film cracking has attracted much attention. Cohesive zones have been utilised to analyse the mechanisms of film cracking and interface delamination. However, till now, compression-induced film cracking have not been observed in detail, especially transverse cracks across buckles. Besides, most cracking induced delamination models are based on two-dimensional plain strain modelling (e.g. [62, 79]), relatively little attention has been paid to cracking evolution process. Therefore, for better understanding of the failure mechanisms, the coupled models of transverse film cracking and interface delamination of films should be developed.

- Cohesive zone modelling limitations: When the cohesive zone law is used to model the growth of a long pre-existing crack in the solid (e.g. [24, 36, 42, 45, 95]), the simulation generally proceeds without difficulty. However, for the case which uses cohesive zones to model crack nucleation, convergence difficulties arise at the point where the crack first nucleates. These problems are known to arise from an elastic snap-back instability, which occurs just after the stress reaches the peak strength of the interface. Suh problem needs to be resolved in existing cohesive zone models by developing reliable approaches based on valid experimental findings.

- Interaction of cracking, delamination and buckling: Currently, many models, each of cracking, delamination and buckling are present in literature. However, interaction of cracking, delamination and buckling of elastic films under multi-scale modelling is still an area of further research. Such interacting approaches in addition to the inclusion of disorders in the interface and material properties, will lead to the realistic prediction of buckling behaviour. The development of incorporated predictive approaches will require detailed experimental analyses, which can then be utilised for model development and validation. 


\section{Corrosive Degradation of Films}

\subsection{Corrosion underneath the films}

Film-substrate systems which are subjected to corrosive environments or standard testing procedures such as ASTM B117, G-85 incur degradation in terms of material loss and interfacial corrosion. In the presence of imperfections in film (such as interfacial voids, microscopic pores and micro-cracks), corrosive species diffuse towards the film-substrate interface through these imperfections and thus result in the initiation of corrosion process due to development of anodic and cathodic sites.

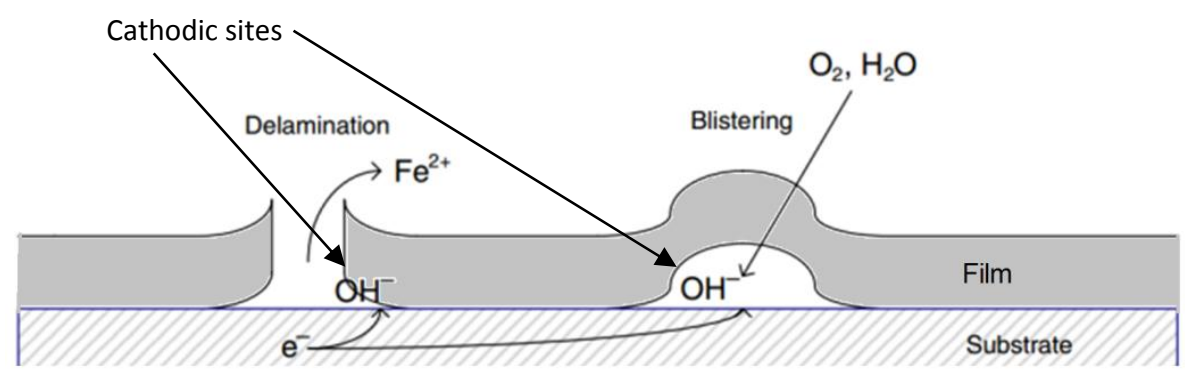

Figure 23. Idealised sketch of cathodic delamination, cathodic blistering [96]

It should be noted that imperfections in the film results in the direct exposure of the steel substrate to its surrounding environment resulting in the initiation of corrosion process, with the anodic reaction occurring at the defect as shown in eq. 44 .

$$
\mathrm{Fe} \rightarrow \mathrm{Fe}^{2+}+2 \mathrm{e}^{-} \quad(\text { Anodic reaction) }
$$

The system maintains the electro-neutrality, by balancing the above reaction (eq. 44) by a cathodic reaction. In most naturally occurring situations, cathodic reaction will be oxygen reduction, as shown in eq. 45 . Both anodic and cathodic reactions initially take place together but separate as the process continues, with the cathode moving under the film.

$$
2 \mathrm{H}_{2} \mathrm{O}+\mathrm{O}_{2}+4 \mathrm{e}^{-} \rightarrow 4 \mathrm{OH}^{-} \quad \text { (Cathodic reaction) }
$$

The ferrous ions $\left(\mathrm{Fe}^{2+}\right)$ produced in eq. 44 form electrically neutral compounds after combining with cations in the medium thus leaving with a charge imbalance. The environment has an excess of positive charge, in the form of whatever cations are present and the environment at the cathode is producing hydroxyl ions, resulting in an excess of negative charge. The ferrous ions and hydroxyl ions formed combine together to produce ferrous hydroxide as,

$$
2 \mathrm{Fe}^{2+}+4 \mathrm{OH}^{-} \rightarrow 2 \mathrm{Fe}(\mathrm{OH})_{2}
$$

The ferrous hydroxide formed reacts with more oxygen (which is diffusing from the environment) to form hydrated ferric oxide, the familiar reddish brown rust (corrosion product) as,

$$
2 \mathrm{Fe}(\mathrm{OH})_{2}+\mathrm{O}_{2} \rightarrow \mathrm{Fe}_{2} \mathrm{O}_{3} \mathrm{H}_{2} \mathrm{O}
$$

In theory, all of these reactions occur simultaneously and can be simply represented in eq. 48. The corrosion products are formed between anodic and cathodic sites.

$$
2 \mathrm{Fe}+\mathrm{O}_{2}+\mathrm{H}_{2} \mathrm{O} \rightarrow \mathrm{Fe}_{2} \mathrm{O}_{3} \cdot \mathrm{H}_{2} \mathrm{O} \text { (Rust) }
$$


The alkaline nature of this resultant solution is considered to be a major contributory factor in the failure of the film. It can be seen that the cathodically produced hydroxyl ions are present at both the blistering and the delamination sites, increasing the alkalinity of solution. In the case of uncoated steel, the route for the countercations is straightforward. However, when the steel is coated the situation becomes more complicated. The path from the exposure environment to the cathodic site is either restricted or blocked completely. Fig. 23 shows a schematic representation of the results of the corrosion reactions.

It should be noted that majority of film failures, due to corrosion underneath the film are interfacial failures, either leading to the complete delamination of film or resulting in the evolvement of film blister. Therefore, our focus will be on the corrosion induced interfacial failure of film bonded to steel surfaces, for which we will utilise the previous concepts of fracture mechanics incorporated with the diffusion concepts (or transport equations). The mechanism of corrosion induced interfacial film failure is based on the disbondment of the film at the imperfection periphery combined with the stress driven diffusive transport of corrosion specie along the film-substrate interface [97, 98]. The bending moment induced by in plane residual stress (due to elastic mismatch) coupled with diffusion induced stress (due to transport of corrosive species) causes the interfacial crack to propagate due to high crack driving force ultimately resulting in buckling. The buckling could either be at the edge or crack front (edge delamination) or could be at the interface (interfacial buckling or blistering) as shown in fig. 23. Micro-cracks in the film accelerate film failures by providing the pathways for the corrosive specie towards the interface. Corrosion process incorporated with edge delamination and blistering mechanisms are commonly known as cathodic delamination and cathodic blistering. The detailed analysis of these two types of film failures will be analysed in the following sequence.

1. Cathodic blistering

2. Cathodic delamination

\subsubsection{Cathodic blistering}

Cathodic blistering is one of the most severe processes responsible for film degradation. In an alkaline environment as the corrosive species diffuse through the film towards the interface, the anodic and cathodic sites are formed at the interface within or near the blister area, thus forming an electrochemical cell [99]. The corrosion products which are formed at the interface cause the film to debond from the substrate forming blister $[98,100]$. After the initiation of blister, it continues to propagate as shown in fig. 24.

Blister growth models are normally developed based on the incorporated concepts of diffusion models and fracture mechanics models for blister propagation.
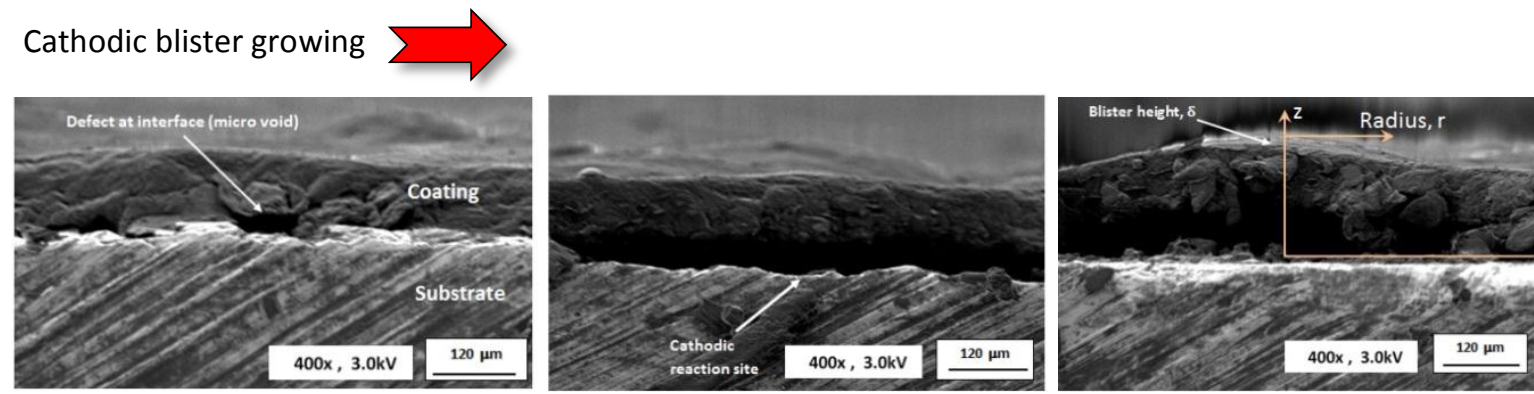

Figure 24. Cross sectional image of blister evolution at the interface of film and substrate system under salt spray exposure [18]

\subsubsection{A general model for cathodic blister}

The model developed by Khan-Nazir [18] couples the diffusion concepts with the fracture mechanics concepts of film (section 2.1.3) to investigate cathodic blister nucleation and propagation. The integration of diffusion and fracture mechanics concepts which form a two-part blistering approach is shown in fig. 25. The diffusion part shows the diffusion of species (portrayed by the arrows) and diffusion induced stress. The fracture 
mechanics part shows the propagation of circular blister as interfacial crack under the coupling effect of compressive and diffusion induced stresses. Fig. 25 also shows the direction of blister propagation in addition to blister radius $\mathrm{r}$ and radial angle $\theta$.

\begin{tabular}{|c|}
\hline $\begin{array}{c}\text { Diffusion } \\
\text { model }\end{array}$ \\
\hline
\end{tabular}
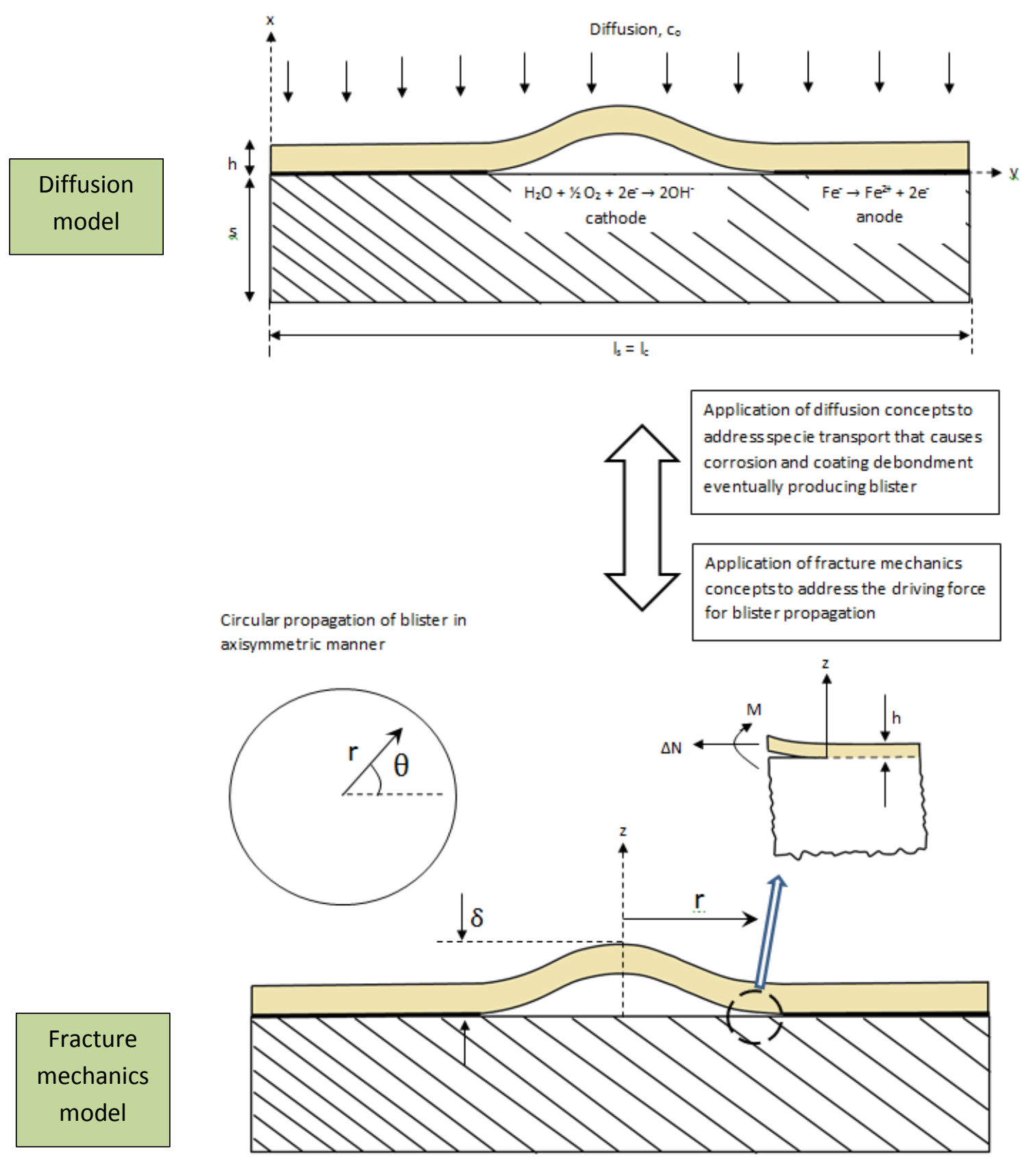

Figure 25. A Two-part theoretical model of blistering coupling the diffusion concept (upper) with the fracture mechanics concept (lower) [18]

\section{A. Diffusion model}

Consider a bilayer cantilever beam with one layer exposed to the diffusing species maintaining a concentration $\mathrm{c}_{\mathrm{o}}$ as shown in fig. 25 (upper). Then according to current design, the top layer of the bilayer cantilever beam acts as a coating while the bottom layer of bilayer cantilever acts as a substrate.

The concentration of corrosive species within the stressed elastic coating (top layer) changes with respect to time, as given below [18]. 


$$
\frac{\partial \mathrm{c}_{\mathrm{c}}}{\partial \mathrm{t}}=\left\{\left(\mathrm{D}_{\mathrm{k}_{\mathrm{c}}}+\frac{\mathrm{D}_{\mathrm{k}_{c}} \mathrm{E}_{\mathrm{c}} \mathrm{v}_{\mathrm{k}_{\mathrm{c}}}{ }^{2}}{9 \mathrm{RT}} \mathrm{c}_{\mathrm{k}_{\mathrm{c}}}\right) \frac{\partial^{2} \mathrm{c}_{\mathrm{c}}}{\partial \mathrm{x}^{2}}+\frac{\mathrm{D}_{\mathrm{k}_{c}} \mathrm{E}_{\mathrm{c}} \mathrm{V}_{\mathrm{k}_{\mathrm{c}}}{ }^{2}}{9 \mathrm{RT}}\left(\frac{\partial \mathrm{c}_{\mathrm{c}}}{\partial \mathrm{x}}\right)^{2}-\frac{\mathrm{D}_{\mathrm{k}_{c}} \mathrm{v}_{\mathrm{k}_{\mathrm{c}}}{ }^{2}}{9 \mathrm{RT}} \frac{\partial \mathrm{c}_{k_{c}}}{\partial \mathrm{x}}\left(\frac{\partial \sigma_{\mathrm{r}_{\mathrm{c}}}}{\partial \mathrm{x}}-\frac{\partial \sigma_{\mathrm{d}_{\mathrm{c}}}}{\partial \mathrm{t}}\right)\right\}
$$

Where, $\partial \sigma_{\mathrm{r}_{\mathrm{c}}} / \partial \mathrm{x}$ is the change in resultant principle residual stresses along the surface of coating and $\frac{\partial \sigma_{\mathrm{d}_{\mathrm{c}}}}{\partial \mathrm{t}}$ is the change in principle diffusion induced stresses in coating with respect to time; $c_{k_{c}}$ represents the concentration of species $\mathrm{k}$ in an infinitely diluted electrolyte solution while $\frac{\partial \mathrm{c}_{\mathrm{k}_{\mathrm{c}}}}{\partial \mathrm{x}}$ represent the change in concentration along the surface of coating; $\mathrm{D}_{\mathrm{k}_{c}}$ is the diffusion coefficient of species $\mathrm{k}$ in coating; $\mathrm{R}$ represents the molar gas constant and $\mathrm{T}$ is the temperature; $\mathrm{V}_{\mathrm{k}_{\mathrm{c}}}$ is a scaler term, independent of stress, representing the partial molar volume of diffusing corrosive species $\mathrm{k}$; $\mathrm{E}_{\mathrm{c}}$ is the elastic modulus of coating.

Eq. 49 can be modified to define a relation which represents the resultant stress change in film $\sigma=\frac{\partial \sigma_{\mathrm{r}_{\mathrm{c}}}}{\partial \mathrm{x}}-\frac{\partial \sigma_{\mathrm{d}_{\mathrm{c}}}}{\partial \mathrm{t}}$ as a function of diffusive- thermodynamic components $\mathrm{c}_{\mathrm{k}_{\mathrm{c}}}, \frac{\partial \mathrm{c}_{\mathrm{k}_{\mathrm{c}}}}{\partial \mathrm{t}}, \frac{\partial \mathrm{c}_{\mathrm{k}_{\mathrm{c}}}}{\partial \mathrm{x}}$ and $\mathrm{V}_{\mathrm{k}_{\mathrm{c}}}$ as,

$$
\sigma=\frac{\partial \sigma_{\mathbf{r}_{c}}}{\partial x}-\frac{\partial \sigma_{d_{c}}}{\partial t}=\left(\left(9 R T+E_{c} V_{k_{c}}^{2} c_{k_{c}}\right) \frac{\partial^{2} c_{k_{c}}}{\partial x^{2}}+E_{c} V_{k_{c}}^{2}\left(\frac{\partial c_{k_{c}}}{\partial x}\right)^{2}-\frac{\partial c_{k_{c}}}{\partial t} 9 R_{T} D_{k_{c}}^{-1}\right)\left(V_{k_{c}}{ }^{2} \frac{\partial c_{k_{c}}}{\partial x}\right)^{-1}
$$

Now, for the prediction of blister growth, eq. 50 can be employed to calculate the effect of resultant stress change $\sigma$ on the debondment crack tips which now integrates the previous diffusion concepts with the fracture mechanics concepts.

For a stress tensor $\sigma$, the pressure $p$ in terms of hoop stress is defined as $p=h \sigma / r$; therefore eq. 50 can be modified in terms of pressure inside blister due to diffusion as,

$$
\mathbf{p}=\frac{h}{r}\left[\left(\left(9 R T+E_{c} V_{k_{c}}^{2} c_{k_{c}}\right) \frac{\partial^{2} c_{k_{c}}}{\partial x^{2}}+E_{c} V_{k_{c}}^{2}\left(\frac{\partial c_{k_{c}}}{\partial x}\right)^{2}-\frac{\partial c_{k_{c}}}{\partial t} 9 \operatorname{RTD}_{\mathbf{k}_{c}}^{-1}\right)\left({V_{k_{c}}}^{2} \frac{\partial c_{k_{c}}}{\partial x}\right)^{-1}\right]
$$

\section{B. Fracture mechanics model}

Fracture mechanics equations of film are used from section 2.3.1. The debondment crack tip is formed as a result of incipient delamination of coating from substrate. The conventional form of normalised stress (eq. 27), can now be modified after incorporating diffusion eq. 50 as,

$$
\frac{p}{p_{c r}}=E_{c}^{-1}\left(1-v_{c}^{2}\right)\left[\left(\left(9 R T+E_{c} V_{k_{c}}{ }^{2} c_{k_{c}}\right) \frac{\partial^{2} c_{k_{c}}}{\partial x^{2}}+E_{c} V_{k_{c}}{ }^{2}\left(\frac{\partial c_{k_{c}}}{\partial x}\right)^{2}-\frac{\partial c_{k_{c}}}{\partial t} 9 R_{T D_{k_{c}}}{ }^{-1}\right)\left({V_{k_{c}}}^{2} \frac{\partial c_{k_{c}}}{\partial x}\right)^{-1}\right]\left(\frac{r}{h}\right)^{3} 52
$$

Where, $\mathrm{r}$ is the radius and represents the radius of a circular interface debondment (blister) as shown in fig. 25 (lower). A circular interface debondment exists between the coating and substrate; $\mathrm{p}_{\mathrm{cr}}$ is the critical pressure corresponding to critical stress $\sigma_{\mathrm{cr}}$ (eq. 26) and depends on the radius of circular interface crack between coating and substrate.

The driving force $\mathrm{G}$ for blister propagation is influenced by a dimensionless mode mix function $\psi$ and $\frac{\mathrm{p}}{\mathrm{p}_{\mathrm{cr}}}$. Therefore by using eq. 21 and 23 of fracture mechanics with the diffusion eq. 51 of film, following relations are developed,

$$
\begin{array}{r}
G=\frac{6\left(1-v_{1}^{2}\right)}{E_{c} h^{3}}\left(M^{2}+\frac{1}{12} h^{2} P^{2}\right) \\
\psi=\frac{K_{2}}{\mathrm{~K}_{1}}=\tan ^{-1} \frac{\cos \omega+\left[\frac{\mathrm{hP}}{\sqrt{12} \mathrm{M}_{\mathrm{c}}}\right] \sin \omega}{\left[\frac{\mathrm{hP}}{\sqrt{12} \mathrm{Mc}}\right] \cos \omega-\sin \omega}
\end{array}
$$




$$
\mathrm{hP} / \sqrt{12} \mathrm{M}_{\mathrm{c}}=0.2\left(1+\mathrm{v}_{\mathrm{c}}\right)\left(\frac{\delta}{h}\right) ; \quad \text { where } \frac{\delta}{h}=\left(\left(0.2\left(1+\mathrm{v}_{\mathrm{c}}\right)+0.2\left(1-\mathrm{v}_{\mathrm{c}}^{2}\right)\right)^{-1}\left(\frac{\mathrm{p}}{\mathrm{p}_{\mathrm{cr}}}-1\right)\right)^{\frac{1}{2}}
$$

The definition of notations have already been defined

From eq. 53 and eq. 53 (a), it can be seen that G, and $\psi$ at the edge of crack depend on the combination-terms $\mathrm{hP} / \sqrt{12} \mathrm{M}_{\mathrm{c}}$ in eq. 53 (b), the term being the function of normalised blister height $\delta / h$. While $\delta / h$ is a function of normalised pressure p/p $\mathrm{p}_{\text {cr }}$ (eq. 52). Above substitutions of eq. 53 (a-b) in to eq. 53 redefine the Hutchinson's delamination propagation problem for $\mathrm{G}$ in terms of resultant pressure $\mathrm{p}$, which is a function of resultant stress change in film $\sigma$.

It can be seen that the cathodic blister propagation as a function of normalised blister pressure $\frac{\mathbf{p}}{\mathbf{p}_{\mathbf{c r}}}$ significantly depends on the substrate to film stiffness ratio $E_{s} / E_{c}$. Higher ratio $E_{s} / E_{c}$ can significantly improve the performance of film in terms of blistering. This indicates that, for a given film thickness, the film's flexibility can decrease the debonding driving force, and thereby improve the performance of film in terms of blistering.

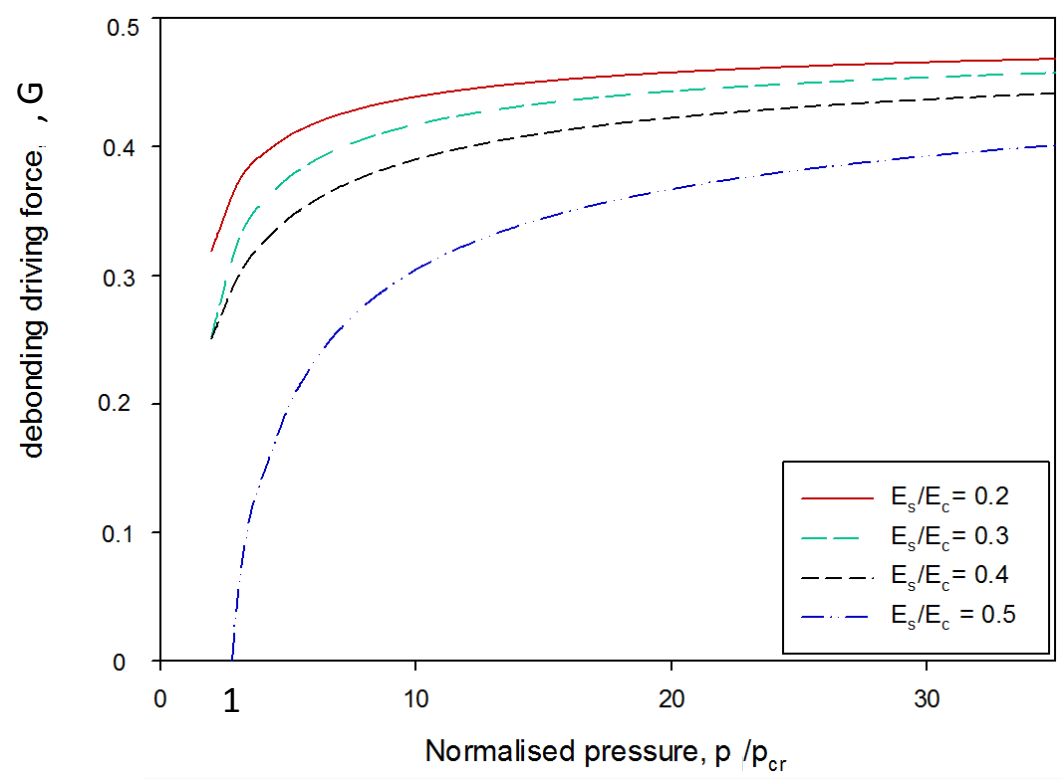

Figure 26. The evolution of debonding driving force to various modulus ratio $\mathbf{E}_{\mathbf{s}} / \mathbf{E}_{\mathbf{c}}$ [18]

\subsubsection{Other models for cathodic blistering}

Literature survey shows that, cathodic blistering was mostly modelled as a complex multidisciplinary problem incorporating the thermodynamics concepts (representing diffusion of species) with the fracture mechanics concepts (representing mode mix propagation of blister). Such incorporated concepts were initially modelled $[98,99]$ by considering the film as a semi-double cantilever beam loaded by a moment at the edge and the load being distributed along the interface due to mass transport of species. The results showed that the blister growth rate is a direct function of applied bending moment $\mathrm{M}$.

Previously, Hutchinson models [22, 23, 36, 39, 40, 43, 44], defining film blistering mechanisms, were purely based on fracture mechanic concepts which were recently modified by Khan-Nazir [15, 20] by developing modified interfacial toughness and mode mix equations for blister propagation under corrosive conditions. The developed equations provided an efficient method for the prediction of blister propagation within the frame work of fracture mechanics and thermodynamics (diffusion). 
The pre-existing film micro- cracks considerably influence film degradation [21]. The effect of tensile residual stress opens the pre-existing film micro-cracks allowing the diffusion of corrosive agents and therefore, accelerating the corrosion damage at interface. The micro-cracks opening is due to the increase in temperature as a result of CTE mismatch between the film and substrate allowing the corrosive species to diffuse towards the interface causing interfacial corrosion and higher blistering rate as shown in fig. 27.

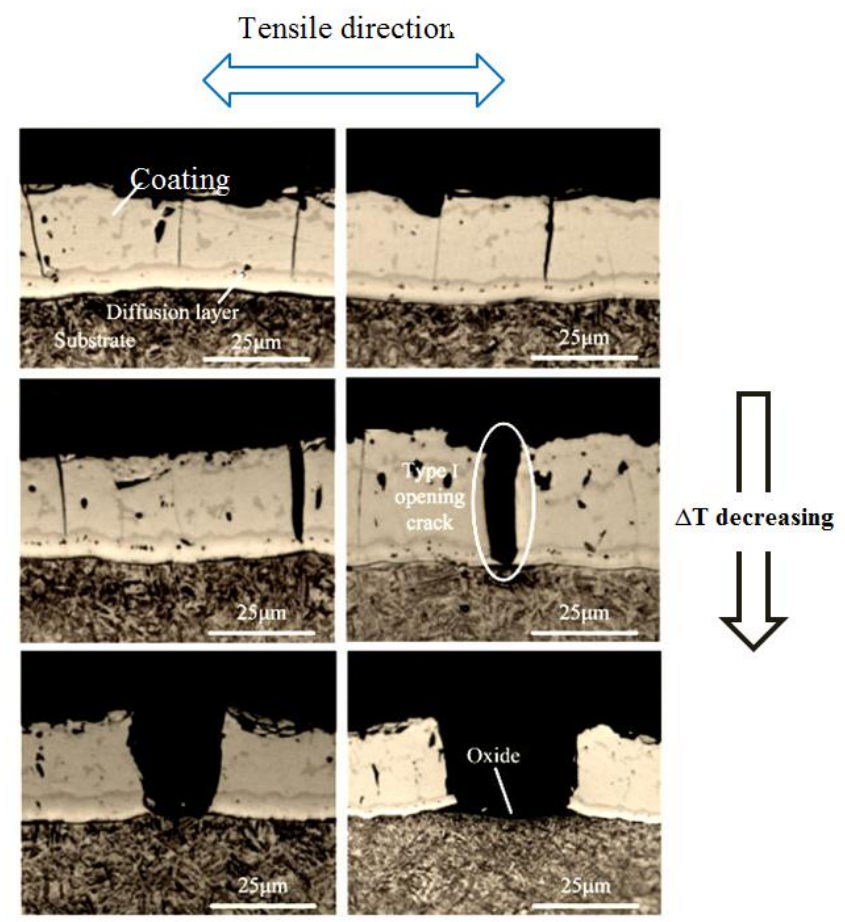

Figure 27. Micro crack opening with increasing temperature due to CTE mismatch allowing corrosive species due diffuse towards the interface causing corrosion [21].

In order to avoid early corrosive failures of films, the best process to adapt is the optimisation of material (such as interface roughness, film thickness) and mechanics properties (tensile and compressive stresses) [16]. These optimised values can be used by the manufacturer at the time of manufacturing to develop durable designs by identifying that under which conditions their manufactured film system will fail and what values of parameters they should use in order to avoid film failure.

Table 2 summarises some of the major models of cathodic blistering developed over a period of time (from 1999 to 2015). A simple relation for elastic energy release rate for blister initiation and propagation as a function of pressure and blister height was developed Wan et al [101]. Later on, Bressers et al [102] developed the relation for elastic energy release rate for blistering as a function of pressure and film thickness which was further modified to develop a relation for blistering with elastic energy release rate as a function of pressure, blister height and stiffness of film [103]. Similar equations were also developed by Jahensen [104] and Volinsky et al [31]. Another equation for elastic energy release rate as function of blister height, stiffness, pressure, film thickness and blister radius, was developed by Kappes et al [105]. Recently, the combined modelling of diffusion concepts with fracture mechanics concepts was modelled by Prawoto [106] with further implementations in [106-109]. The Prawoto further extended his model [106] to include the J-integral concept to simulate blistering mechanism for efficient design [110]. 
Table 2. Some major blistering models from literature particularly useful for predicting blister initial and propagation [18]

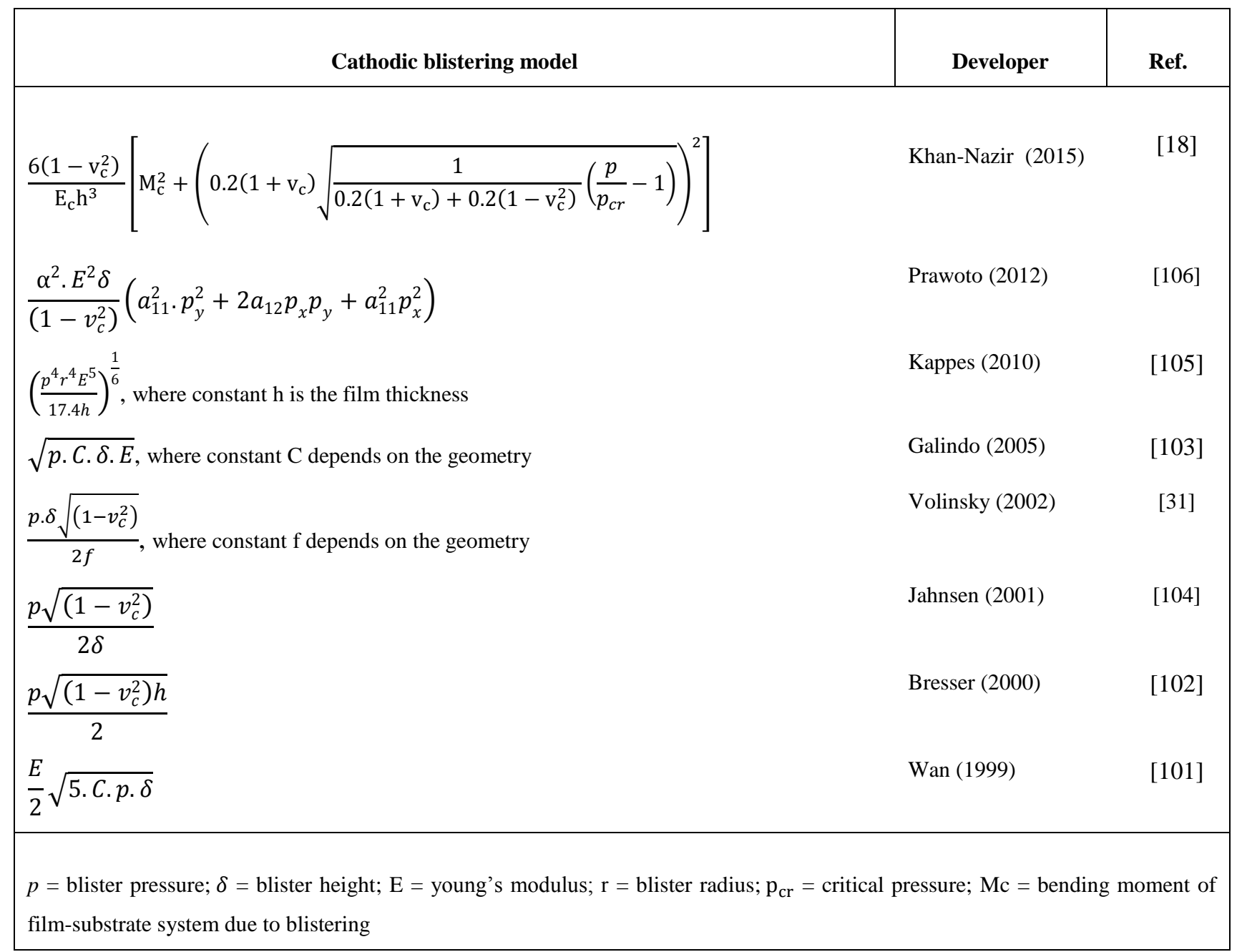

\subsubsection{Cathodic delamination}

The process of cathodic delamination is another most significant causes of film degradation [111]. The bulk amount of atmospheric pollutants at the film defect is the source of many corrosive species that take part in the electrolytic alkalinisation of solution as shown in fig. 28. The constant transportation of corrosive species from the defect in to the delaminated region forms an electrochemical cell. The anodic sites are formed on the metal substrate where it is oxidised, while at the cathodic sites, the oxygen is reduced. The cathodic induced sites act as "nucleation sites for cathodic delamination". The corrosive species transport from the defect in film in to the delaminated region which controls the cathodic delamination process [112]. Usually the delamination process forms a linear relation with time which can be explained by the alkalization effect on the electrolyte solution as a result of oxygen reduction. 

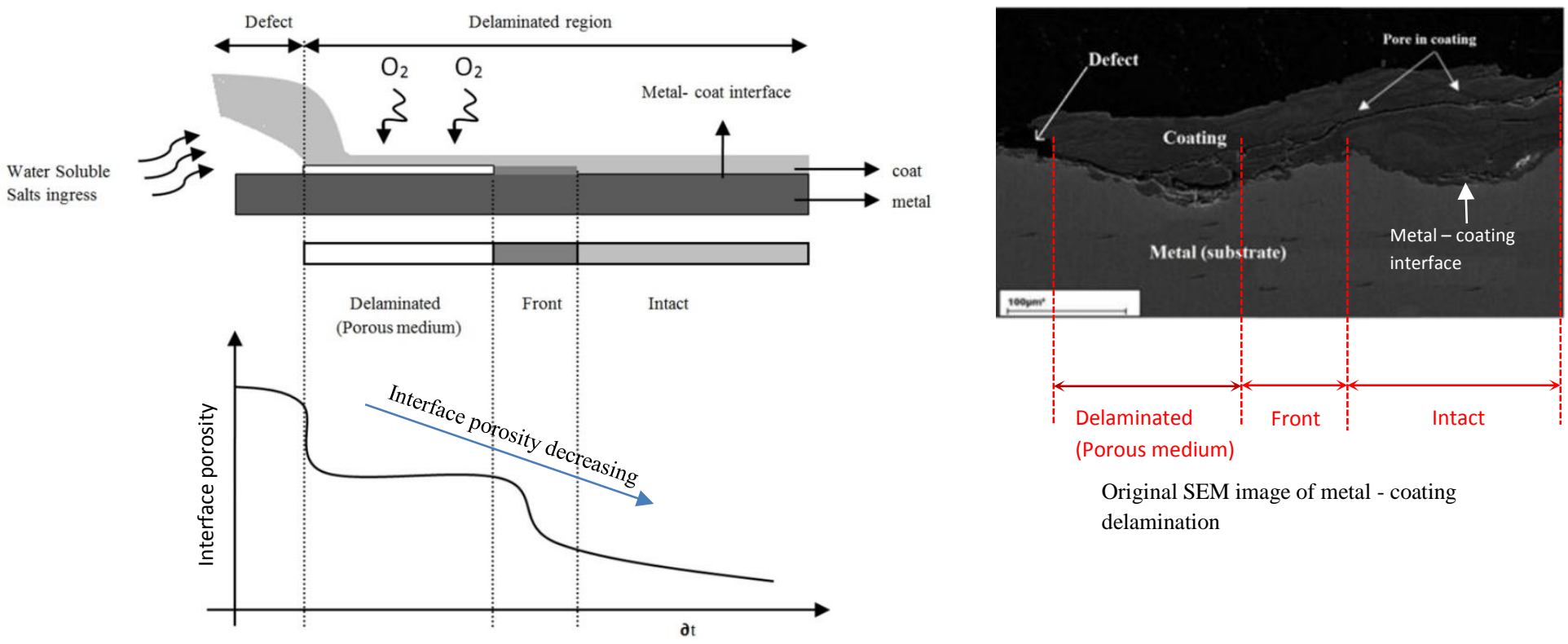

Original SEM image of metal - coating delamination

Figure 28. Schematic (left) and microscopic (right) image of cathodic delamination [14, 17].

The cathodic delamination at the interface can be divided in to three regions depending on the coating uplift' (or interface porosity) i.e. delaminated, front and intact region as shown in fig 27. The disbonded area represents the defect in film which allows the bare metal to be exposed to electrolyte. Besides the defected area lays the delaminated region where the film-substrate bonding is partly weakened as a result of cathodic delamination process. The innermost region, which is fully intact with the substrate and has no delamination, yet occurred. The interfacial porosity is highest in the delaminated region and is zero or negligible in the intact region (fig. 28 ). With the passage of time, the delamination front as a result of electrochemical activity propagates in to the intact region resulting in the growth of cathodic delamination.

The pioneering work of cathodic delamination was performed by Stratmann et al [113-120]. The delamination of film-substrate (steel) near an artificial defect investigated using Scanning Kelvin Probe showed that the galvanic coupling (A galvanic couple is a corrosive cell that is developed when two different materials are separated by electrolyte) in film results in the defect in film due to the high permeability of the film to oxygen. The cathodic current density at the interface beneath the film is directly related to the delamination rate [121123]. The rate determining step of delamination involves the bond breakage of film and substrate as a result of alkaline electrolyte solution formation beneath the film [124, 125]. The resistivity of electrolyte is an important factor that play a vital role during delamination process and is discussed in detail in [126, 127].

The first comprehensive mathematical model for cathodic delamination comprising of a non-linear porosity- $\mathrm{pH}$ relationship was developed by Allahar et al $[128,129]$ based upon the experimental results [113-120]. The interfacial porosity which depends on hydroxyl $\mathrm{OH}$ - ions formation decides the interfacial bonding and bond breakage of film and substrate [130]. The bond breakage decides the delamination rate. If the transport rate of corrosive species through defect and formation of $\mathrm{OH}-$ ions is small, then bond breakage of film and substrate will also be small.

Khan-Nazir [17], recently developed an efficient time iterative model and showed that the concentration of cations (e.g. $\mathrm{Na}^{+}$in $\mathrm{NaCl}$ solution) and their transport significantly affect the debonding of film-substrate system thus deciding delamination rate. Higher transport rate of cations account for large degree of $\mathrm{OH}$ - production (to maintain electro-neutrality) which then results in large bond-breakage rate. A further extension [14] brought substantial flexibility in delamination modelling of complex situations of film-substrate system exposure, allowing to not only model the electrochemical reactions at interface of film and substrate (as above) but also these factors were incorporated like the type of environmental salts and their varying concentration with annual 
weather changes (summer and winter), the time of exposure of the film-substrate system, the type of filmsubstrate system i.e. static or dynamic system, the frequency with which certain film-substrate system is exposed to various environmental conditions e.g. controlled or uncontrolled.

\subsection{Tribo-corrosion degradation}

Tribo-corrosion includes the coupling relation between the mechanical wear and the electrochemical corrosive process which may lead to loss of materials such as films. Fig. 29 illustrates passive layer and film removal that can accelerate wear-corrosion under three body rolling abrasion while fig. 30 illustrates the types of corrosionwear process. Although tribo-corrosion is based on cyclic loading instaead of the quasi-static indentation loading or the thermal and stress loading, but still, when subjected to corrosive conditions, the most common modes of failure is adhesion loss due to either delamination or blistering of film systems. Therefore, it is important to review this subject under the umbrella of this article.

The subject attracted the attention of researchers in the late 1980s and has now become one of the most active research area in the field of materials science and engineering. Previous tribological studies [131] only focused on the wear properties of films by using tribometers however with the development of advanced experimental methods, the friction, wear, adhesion and lubrication phenomena at the nanoscale, where atomic interactions and quantum effects are not negligible were performed $[132,133]$. Such advancements also helped in understanding and examining the complex processes present in tribo-corrosion contacts under the subject of wear-corrosion (or tribo-corrosion).The in situ corrosion and post-test analysis methods for the study of the surface film provide with the state-of-the-art tools that can be utilised in tribo-corrosion experimental tests. Tribo-corrosion, thus, incorporates the adhesion, abrasion, fatigue wear, fretting processes, corrosion in addition to erosion (droplets, cavitation bubbles or solids). For example, during friction, the chemical effects may often influence the strain energy release rate [134].

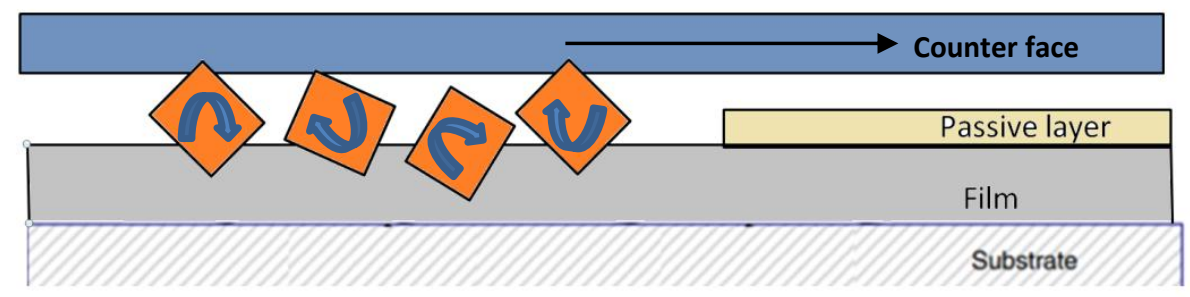

Figure 29. Tribo-corrosion sketch for de-passivation of passivated film surface by three body rolling which induces abrasion between film surface and counter face.

Stainless steels are mainly protected by a very thin $(0.001 \mu \mathrm{m}$ to $0.01 \mu \mathrm{m})$ passive oxide film which helps protect the surfaces from corrosive and aggressive environments. The oxide layer develops spontaneously when oxygen is present in environment however wear can result in the removal and complete rupture of the se films. Such phenomenon can lead to the regions on substrate being exposed to the corrosive environment and if the passive layer does not develop back again (repassivation or self-healing), the anodic steel dissolution reactions will continue at these sites. The response of passivating steel surface purely depends on the depassivation rate due to wear and repassivation rate due to self-healing of passive film. It is worth noting that if former is higher, then this will result in higher dissolution rates of steel due to its direct exposure to corrosive environment. Therefore, in addition to the integrity and exposure of coating, the passive film condition on coating surface also plays a vital role in wear-corrosion performance of the coating. Fig. 29 shows the depassivation of passivated film by three body rolling while fig. 30 shows how an impacting solid particle can harm passive films of metallic surfaces. However, the literature shows that till now, there is no validated theory that can confirm that the surfaces that readily passivate also offer good wear-corrosion resistance. This lack of understanding has seriously hindered in developing optimised solutions to maximise the efficiency of machines in aggressive environments. 
The three key types of wear-corrosion mechanisms of film-substrate systems were proposed i.e. Type I, Type II and Type III [135]. Type I wear-corrosion involves the passivation of damaged passive layer on the hard film as shown in fig. 30 (a). Type II wear-corrosion involves the removal of film blisters in the form of film fragments upon the interaction with counter face material as shown in fig. 30 (b). Type III mechanism involves the galvanic roughening of film upon interaction with the counter face during sliding which causes abrasion as shown in fig. 30 (c).

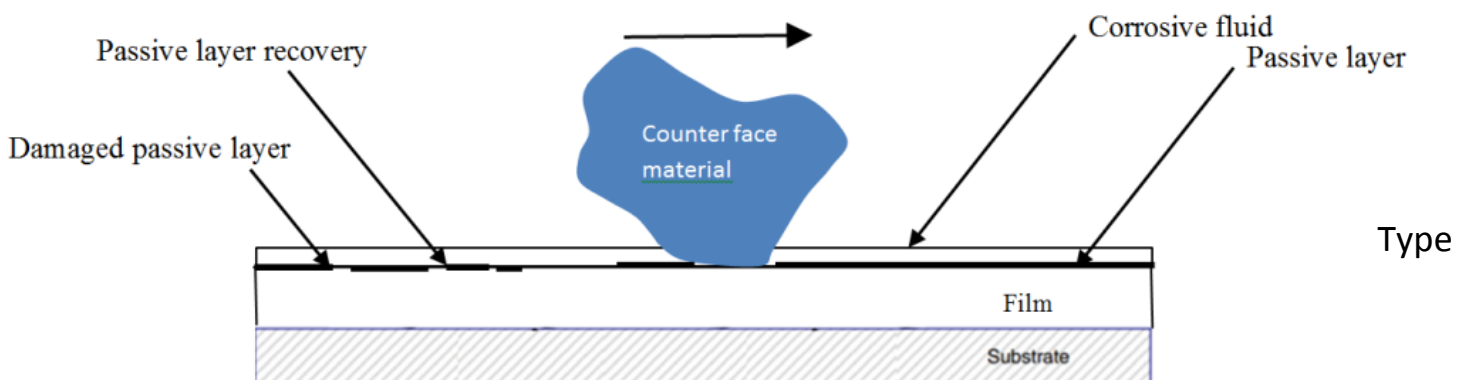

(a)

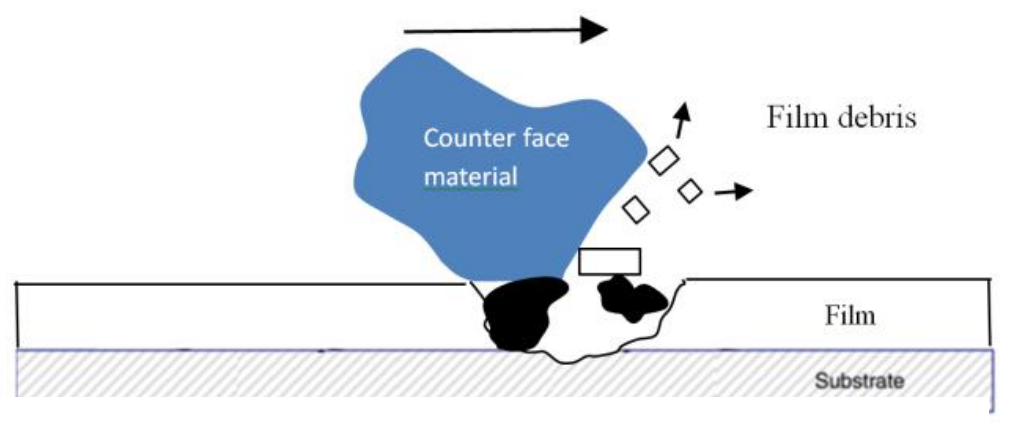

Type II

(b)

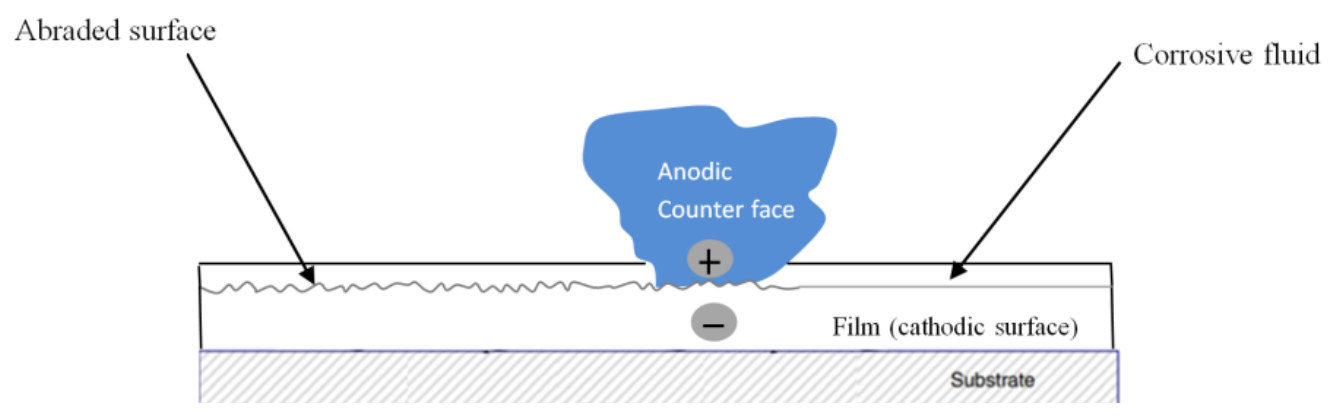

Type III

(c)

Figure 30. Types of wear-corrosion of film (a) type I wear-corrosion (b) type II wear corrosion (c) type III wear corrosion

The wear-corrosion performance of various films significantly depends upon the passive oxide layer on surface of film which forms a barrier (of high impedance) for the transfer of charge during electrochemical activity (resulting in corrosion) between the anodic and cathodic sites on the interface of film-substrate. The passive layer which is beneficial for film integrity is lost upon tribo-corrosion contacts by mechanical wear. When the passive layer is mechanically removed, the transfer of charges at interface initiates and progresses. Such coupled behaviour of tribological and electrochemical corrosion influences the film-substrate material to corrode, however the corrosion rate can be different for distinct materials. The above understanding is largely being utilised to analyse the corrosive reactions during erosion-corrosion interactions. 
The oxide layer is vulnerable and can be completely removed or damaged, when subjected to tribological contact leading to accelerated corrosion in areas where oxide layer has been damaged. Furthermore the contact between the sliding surfaces at multiple asperities is important in addition to the passivation behaviour of the material. Other parameters such as applied perpendicular force, frequency and sliding speed also influence the dissolution rate. The galvanic activity due to damaged/worn sites enclosed within unworn sites play a vital role in tribo-corrosion contacts [136]. The passive oxide layer significantly influences steel degradation during tribocorrosion testing.

A model was developed by Garcia et al [137] for an electrode of area A which was subjected to a reciprocating wearing contact with a frequency of $\mathrm{f}$, allowing the corrosion current I to flow through it at a specific anodic potential as,

$$
I=f A_{a} \int_{0}^{\frac{1}{f}} i_{a}(t) d t+f\left(A-A_{a}\right) \int_{0}^{\frac{1}{f}} i_{p}(t) d t
$$

Where $A_{a}$ represents the worn area, $i_{a}(t)$ is the re-passivation current density, $\mathrm{A}-A_{a}$ is the passive area and $i_{p}(t)$ is the passive current density corresponding to a specific anodic potential. The corrosion current density in relation to worn area show that both an electrode having an area A (with specific anodic potential) and worn area $\mathrm{A}_{\mathrm{a}}$ produced due to the tribo-contact under specific frequency inversely influence the current density on electrode with the passivation area $\mathrm{A}-\mathrm{A}_{\mathrm{a}}$ at given anodic potential.

The above model was further modified by Goldberg [138] for corrosion currents generated as a result of scratching passive surfaces as,

$$
\mathbf{I}_{\text {peak }}=\mathbf{j}_{\text {crit }} \mathbf{A}_{\mathbf{o}} \mathbf{e}^{\left[\frac{\mathrm{n}_{\mathbf{f}}}{\mathrm{b}_{\mathbf{a}}}\right]}+\frac{\varrho \rho Z F A_{0}}{M_{w}}
$$

Where $I_{\text {peak }}$ is the peak current $\left(I_{\text {peak }}=I_{\max }-I_{\infty}\right), t_{o}$ is the re-passivation time, $I_{\text {max }}$ is the maximum recorded current, $I_{\infty}$ is the passive current at $t=\infty, A_{o}$ is the scratch area, $j_{\text {crit }}$ is the current density for passivation, $\varrho$ is the re-passivated oxide thickness, $b_{a}$ is the Tafel slope, $n_{f}$ is the scratch over potential, $\rho$ is the oxide density, $\mathrm{F}$ is Faraday's constant, $\mathrm{Z}$ is the charge per cation, and $\mathrm{M}_{\mathrm{w}}$ is the oxide molar mass. The current evolved as a result of sliding between two passive materials depends on the time for re-passivation $t_{o}$ and the thickness of passive oxide layer @. The current density decreases with the increase in the thickness of passive oxide layer preventing the corrosive fluid from reaching the surface during scratching.

Another advanced model was developed by Mischler et al [139] for reciprocating contacts including the influences of material hardness and load. Mischler developed the relation for the anodic current $I_{a}$, produced as result of interaction with the much harder counter body.

$$
I_{(a, w)}=K_{w} \text { If }\left(\frac{W}{H}\right)^{\frac{1}{2}} \int_{0}^{\frac{1}{f}} i d \tau
$$

More accurate and complicated models are being developed for tribo-corrosion interactions in aqueous sliding contacts, and are reviewed in [140].

The generation of wear debris particles can cause the initiation of micro-crack and propagation [140]. The wear process including wear debris is significantly accelerated by the presence of corrosive environment because: (a) the localised corrosion failures causes the micro-cracks to nucleate at higher rate from the debris and (b) electrochemical activity due to corrosive species speeds up the propagation of already existing micro-cracks due to debris.

Bozzini et al [141] utilised a straightforward estimated model by employing a 'recovering target' concept. The analysis advantages many conventional approaches in a way that it can be applied to both actively corroding and passivating conditions. The concept of rigid monodisperse spheres of radius $r_{p}$ is utilised to model the impacting particles. The spherical particles with radius which make impact on film have parameter $\lambda$ impacts $\mathrm{m}^{-2} \mathrm{~s}^{-1}$ and are considered as Poissonian. Every impacting particle creates a variation in corrosion rate which in turn affects the corrosion current density for specific period of time. The corrosion current density $i_{\text {corr }}$ corresponding to a 
specific electrode potential can be associated with mechanically influenced corrosion component of a damaged surface thorough parameter ' $f_{a}$ ' ( such that $\left.0 \leq f_{a} \leq 1\right)$ expressing the fraction of the surface getting corroded and being influenced through the erosive behaviour of impacting particles.

$$
\mathbf{i}_{\text {corr }}=\mathbf{C}+\Delta \mathbf{C}_{\mathrm{e}}=\mathbf{f}_{\mathrm{a}} \mathbf{i}_{\mathrm{a}}+\left(\mathbf{1}-\mathbf{f}_{\mathrm{a}}\right) \mathbf{i}_{\mathrm{u}}
$$

where the subscripts a and u stand for 'affected' and 'unaffected', respectively. The current densities $i_{a}$ and $i_{u}$ are characteristic of the corroding material in the absence and in the presence of the erosive action and can be measured separately by means of suitable experiments. In general, the coefficient $f_{a}$ can be defined in equation

$$
f_{a}=\left(\frac{\text { no.ofimpacts }}{\text { control area }}\right) \times\left(\frac{\text { damaged area }}{\text { impact }}\right) \times \text { recovery time }=\lambda A_{a} \tau
$$

Where $A_{a}$ is the affected surface area and $\tau$ is the passive recovery time

Literature survey shows that mostly experimental tests were either developed for wear analysis of films or corrosion analysis of film without any coupling analysis of the both. However, when such films were deployed in wear-corrosion conditions, their performance was extremely unsatisfactory because many films which are corrosion resistant are not wear resistant and vice versa. Consequently, such models were developed which were able to predict the coupled wear-corrosion behaviour of materials under aggressive conditions. Nevertheless, these models need significant advancement before they can be utilised for robust predictions as the research area 'mechano-electrochemical interactions' still have many questions that need answers.

\subsection{Future scientific challenges in degradation modelling}

Corrosion-driven film degradation is the process in which more-or-less intact film becomes physically separated from the underlying substrate, due to its exposure in corrosive environment. Two main types of film degradation are: cathodic delamination and cathodic blistering in addition to tribo-corrosion degradation (under wearcorrosive conditions). All of these phenomena tend to propagate from pre-existing breaks or penetrative defects in the film, which allows the diffusion of species from an external electrolyte. In the case of cathodic delamination, separation of the film is linked to the cathodic reaction in a localized corrosion cell. As such, cathodic delamination $[17,129,130]$ is closely related to the phenomena of cathodic blistering $[16,18,21]$. Tribocorrosion degradation is linked to the mechanical wear and the electrochemical corrosive degradation of films. Some important improvements which can be incorporated in the exiting techniques are listed as follows.

- Micro-cracks effects: Most degradation models are based on multidisciplinary approaches which incorporate the diffusion concepts with the fracture mechanics concepts $[15,16,18,19,21,99$, 106-108, 142]. However such incorporated models only simulate film failures under residual and diffusion induced stresses without the inclusion of micro-cracks effects. Micro-cracks, under tension, can open wide and accelerate interfacial corrosion resulting in high film failure rate. [21]. Contrarily, under compression, micro-cracks close which result in the low interfacial corrosion but at the cost of high blistering. Therefore, models including combined effects of micro-cracks with both residual and diffusion induced stresses should be developed.

- Multi-layer films: Studies of models for cathodic delamination and cathodic blistering show that most of the models for these types of degradations are available for single layer film systems. However, most of the commercial film-substrate systems comprise of multi-layer films. Therefore, for accurate predictions of commercial applications, cathodic delamination and blistering should be modelled considering multi-layer films.

- Potential distribution within delaminating region: It has been shown previously [112, 113], that the cathodic delamination can be understood in terms of polarisation curves. For steel, the polarisation curves are independent of $\mathrm{pH}$ values when ranging in between 6 to 12.5. The missing information for complete understanding of delamination is the potential distribution radially distributed from the defect to the intact region of film and substrate. The numerical modelling for delamination in the above context is a challenging task due to the following parameters: the 
thickness of the aqueous layer at the interface as a function of distance from the defect; the conductivity of the liquid; the amount of charge that passes through the film radially from the defect; the oxygen concentration gradient across the film.

- Nature of film-substrate bonding: The interfacial region in most film-substrate systems consists of a metal substrate, a thin oxide film on metal and the top film. The interfacial bonding between substrate and film is commonly referred to as hydrogen bond, Van dar Waals bond, electrostatic bond, etc. Till now, there is no exact experimental information in specific instances to characterize the bond quantitatively. The area which needs attention is the change in nature of bond with the diffusion of species through the film in addition to adsorption and electrochemical reactions along the interfacial region.

\section{Conclusions}

This review paper presents a detailed literature survey focused on modelling techniques of two main areas i.e. cracking and corrosive degradation of film system. The review also presents the suggestions for improvements in current experimental and theoretical models to overcome some of the limitations in film failure analysis. Literature survey encouraged to draw the below given conclusions:

- As the nature of film system is bi-material, the resulting crack propagation at the interface of film and substrate is mostly mixed mode, and may result in the formation of extremely complicated and unusual patterns, for example telephone cord blisters, spiral blisters. Fortunately, the development of applicable predictive models for the analysis of interfacial fracture phenomenon has been developed over the period of time, making it possible to evaluate the fracture strength of interfaces by utilising the fracture data from various standard interfacial testing methods. Such analysis proves extremely useful in the development of up-to-date interfacial cracking models, for a diverse range of systems such as randomly loaded coated beams, film blistering phenomenon as a result of compressive stresses, and impact or indentation-induced edge buckling of films.

- Analyses, like the above interfacial fracture phenomenon, also exists for a vast range of cracking patterns (such as surface cracking, substrate spalling). The outcomes of these analyses are very beneficial in terms of predicting the cases such as what type of cracking pattern is most likely to be encountered by a particular film system, and what aiding procedure should be adapted during the designing of film to avoid such failure. Table 1 can prove helpful for the manufacturers to avoid early failures of film systems and can act as a guide to film system design.

- It should be noted, that the commonly applicable analysis of interfacial fracture discussed in section 2.1 , works accurately only for predicting the behaviour of a steady state propagating crack. However, for the case when there is no incipient crack at the interface, then the free edge singularity analysis is used which is discussed in detail section 2.3. This analysis can be used to predict the crack nucleation at the interface. One important point that should be noted in terms of film system designing is that the design solutions of interfacial fracture mechanics based on the free edge problem (no cracks at the interface) can be quite different compared to the steady state crack propagation. Therefore, the design which performs well to avoid steady state crack propagation may not necessarily perform well to avoid crack initiation.

- The steady state interfacial crack propagation such as blistering takes place under the thermal compressive residual stresses due to coefficient of thermal expansion mismatch between film and substrate. However, blistering, in addition to thermal stresses, can also be driven by diffusion of corrosive species diffusion towards the interface. The incorporation of diffusion parameters with the fracture mechanics parameters provide with the platform for modelling of cathodic blistering in filmsubstrate systems as shown in fig. 31. Cathodic blisters evolve in the films when the film-substrate is exposed to corrosive environmental conditions such as salt spray. 


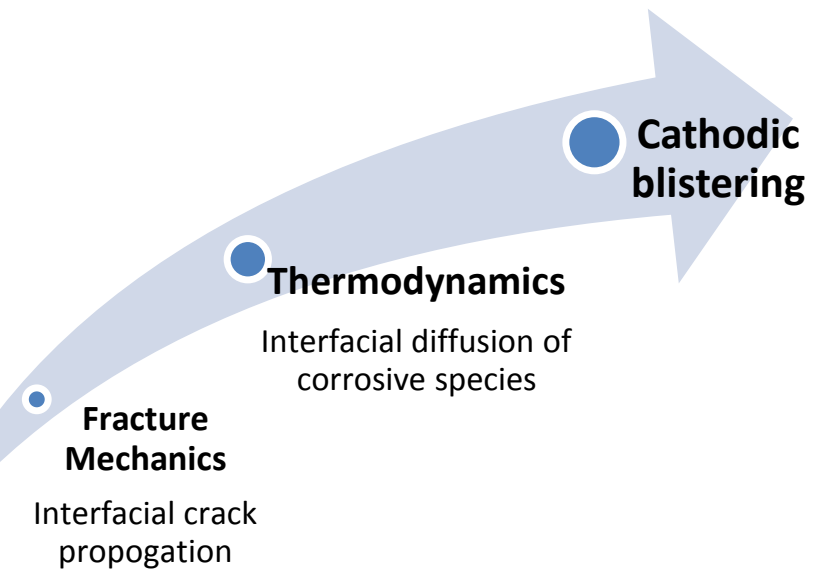

Figure 31. The incorporation of fracture mechanics concepts (discussed in detail in section 2) with the thermodynamics concepts (discussed in detail in section 3 ) to address cathodic blistering failures

- Another film behaviour under corrosive conditions coupled with the mechanical wear leads to loss of materials due to removal of passive layer and film. Such wear-corrosion mechanism may lead to significant corrosive wear under three body rolling abrasion and is known as tribo-corrosion.

\begin{abstract}
About the Authors
Dr Zulfiqar Khan: Zulfiqar Khan is Associate Professor and is a mechanical engineer. He has worked in automotive and aircraft industries for several years. He has worked with GTZ United Nations energy savings technologies. His research expertise includes corrosion fatigue, rolling contact fatigue, tribology and Nanocoatings with over 100 publications and a book on pressure vessel steel. This review paper is part of a wider multidisciplinary research and focuses on predictive mathematical modelling of coating failure to enhance durability and reliability especially in high value systems and products where higher factor of safety is highly desirable. Authors acknowledge that the depth and diversity of disciplines covered here offers an academic challenge and is beyond the boundaries of specific subject areas. It is understandable that the learning process continues and the authors are delighted to have put this academic and research piece to be available to scientists, academics, researchers, professionals and students to engage in the design for durability and reliability through a multidisciplinary approach to bring about societal, economic and environmental impacts.
\end{abstract}

Dr Mian Hammad Nazir: Hammad Nazir is working as a Post-Doctoral Research Associate in NanoCorr, Energy and Modelling (NCEM) Research Group in Bournemouth University UK. He obtained his PhD in structural health monitoring from Bournemouth University in April 2016. His area of research is computational and numerical modelling, in-situ and real time health monitoring of coatings and thin films subject to mechanical, corrosion and wear failures. He has more than 15 journal publications in coating failure analysis. This review is an attempt to cover a huge field of coatings failures including some very important papers from literature as well as latest related publications within NCEM. The authors believe that this review will help researchers, academics, designers and industrial manufacturers for qualitative improvements and appropriate developments in the field of coatings and thin films.

Acknowledgement: The authors are very grateful to the reviewers for their careful and meticulous reading of the paper. The reviews were detailed and helpful to finalize the manuscript. The authors would like to kindly acknowledge them. 


\section{Compliance with Ethical Standards:}

The authors declare that they have no conflict of interest.

\section{References}

[1] A. Saeed, Khan, Z., and Montgomery, E., "Corrosion Damage Analysis and material Characterization of Sherman and Centaur - The Historic Military Tanks," Materials Performance and Characterization, vol. 2, pp. 30-44, February 6, 2013.

[2] A. Saeed, Z. A. Khan, M. Hadfield, and S. Davies, "Material characterization and real-time wear evaluation of pistons and cylinder liners of the tiger 131 military tank," Tribology Transactions, vol. 56, pp. 637-644, // 2013.

[3] A. Saeed, Z. Khan, M. Clark, N. Nel, and R. Smith, "Non-destructive material characterisation and material loss evaluation in large historic military vehicles," Insight: Non-Destructive Testing and Condition Monitoring, vol. 53, pp. 382-386, 2011.

[4] M. H. Nazir, Z. A. Khan, A. Saeed, and K. Stokes, "A predictive model for life assessment of automotive exhaust mufflers subject to internal corrosion failure due to exhaust gas condensation," Engineering Failure Analysis, vol. 63, pp. 43-60, 2016.

[5] A. Saeed, Z. A. Khan, and M. H. Nazir, "Time dependent surface corrosion analysis and modelling of automotive steel under a simplistic model of variations in environmental parameters," Materials Chemistry and Physics, vol. 178, pp. 65-73, 8/1/ 2016.

[6] Z. A. Khan, M. Hadfield, S. Tobe, and Y. Wang, "Ceramic rolling elements with ring crack defects - A residual stress approach," Materials Science and Engineering A, vol. 404, pp. 221-226, 2005.

[7] Z. A. Khan, M. Grover, and M. H. Nazir, "The Implications of Wet and Dry Turning on the Surface Quality of EN8 Steel," in Transactions on Engineering Technologies, ed: Springer, 2015, pp. 413-423.

[8] Z. A. Khan and M. Hadfield, "Manufacturing induced residual stress influence on the rolling contact fatigue life performance of lubricated silicon nitride bearing materials," Materials \& Design, vol. 28, pp. 2688-2693, 2007

[9] Z. A. Khan, M. Hadfield, and Y. Wang, "Pressurised chamber design for conducting rolling contact experiments with liquid refrigerant lubrication," Materials and Design, vol. 26, pp. 680-689, 2005.

[10] Z. A. Khan, P. Pashaei, R. Bajwa, H. Nazir, and M. Cakmak, "Fabrication and characterisation of electrodeposited and magnertron-sputtered thin films," International Journal of Computational Methods \& Experimental Measurements, vol. 3, pp. 165-174, 2015.

[11] R. S. Bajwa, Z. Khan, V. Bakolas, and W. Braun, "Water-lubricated Ni-based composite (Ni-Al2O3, $\mathrm{Ni}-\mathrm{SiC}$ and $\mathrm{Ni}-\mathrm{ZrO} 2$ ) thin film coatings for industrial applications," Acta Metallurgica Sinica (English Letters), vol. 29, pp. 8-16, 2016.

[12] R. S. Bajwa, Z. Khan, V. Bakolas, and W. Braun, "Effect of bath ionic strength on adhesion and tribological properties of pure nickel and Ni-based nanocomposite coatings," Journal of Adhesion Science and Technology, vol. 30, pp. 653-665, 2016.

[13] R. Bajwa, Z. Khan, H. Nazir, V. Chacko, and A. Saeed, "Wear and Friction Properties of Electrodeposited Ni-Based Coatings Subject to Nano-enhanced Lubricant and Composite Coating," Acta Metallurgica Sinica (English Letters), vol. 29, pp. 902-910, 2016.

[14] M. Nazir, Z. Khan, and K. Stokes, "Modelling of metal-coating delamination incorporating variable environmental parameters," Journal of Adhesion Science and Technology, vol. 29, pp. 392-423, 2015.

[15] M. Nazir, Z. A. Khan, and K. Stokes, "A unified mathematical modelling and simulation for cathodic blistering mechanism incorporating diffusion and fracture mechanics concepts," Journal of Adhesion Science and Technology, vol. 29, pp. 1200-1228, 2015.

[16] M. Nazir, Z. A. Khan, and K. Stokes, "Optimisation of interface roughness and coating thickness to maximise coating-substrate adhesion-a failure prediction and reliability assessment modelling," Journal of Adhesion Science and Technology, vol. 29, pp. 1415-1445, 2015.

[17] M. Nazir, Z. A. Khan, and K. Stokes, "A holistic mathematical modelling and simulation for cathodic delamination mechanism-a novel and an efficient approach," Journal of Adhesion Science and Technology, vol. 29, pp. 2475-2513, 2015.

[18] M. H. Nazir, Z. A. Khan, A. Saeed, and K. Stokes, "A model for cathodic blister growth in coating degradation using mesomechanics approach," Materials and Corrosion, vol. doi: 10.1002/maco.201508562, pp. n/a-n/a, 2015. 
[19] M. H. Nazir, Z. A. Khan, and K. Stokes, "Maximising the interfacial toughness of thin coatings and substrate through optimisation of defined parameters," International Journal of Computational Methods \& Experimental Measurements (WIT Press), vol. [In Press], 2015.

[20] M. H. Nazir, Z. A. Khan, and K. Stokes, "Analysing the coupled effects of compressive and diffusion induced stresses on the nucleation and propagation of circular coating blisters in the presence of microcracks," Engineering Failure Analysis, vol. 70, pp. 1-15, 2016.

[21] M. H. Nazir, Z. A. Khan, A. Saeed, R. S. Bajwa, K. Stokes, and K. Stokes, "Modelling the Effect of Residual and Diffusion induced Stresses on Corrosion at the Interface of Coating and Substrate," CORROSION, NACE [In Press], 2015.

[22] J. W. Hutchinson and Z. Suo, "Mixed mode cracking in layered materials," Advances in applied mechanics, vol. 29, p. 191, 1992.

[23] J. Hutchinson, M. Thouless, and E. Liniger, "Growth and configurational stability of circular, bucklingdriven film delaminations," Acta metallurgica et materialia, vol. 40, pp. 295-308, 1992.

[24] Z. Suo and J. W. Hutchinson, "Interface crack between two elastic layers," International Journal of Fracture, vol. 43, pp. 1-18, 1990.

[25] M. Papini, G. Fernlund, and J. Spelt, "Effect of crack-growth mechanism on the prediction of fracture load of adhesive joints," Composites science and technology, vol. 52, pp. 561-570, 1994.

[26] A. Argon, V. Gupta, H. Landis, and J. Cornie, "Intrinsic toughness of interfaces between SiC coatings and substrates of Si or C fibre," Journal of materials science, vol. 24, pp. 1207-1218, 1989.

[27] Z. Chen, K. Zhou, X. Lu, and Y. C. Lam, "A review on the mechanical methods for evaluating coating adhesion," Acta mechanica, vol. 225, pp. 431-452, 2014// 2014.

[28] C. Jinju, L. Zheshuai, S. J. Bull, C. L. Phillips, and P. D. Bristowe, "Experimental and modelling techniques for assessing the adhesion of very thin coatings on glass," Journal of Physics D: Applied Physics, vol. 42, p. 214003, 2009.

[29] R. Lacombe, Adhesion measurement methods: theory and practice: CRC Press, 2005.

[30] C. Jinju, "Indentation-based methods to assess fracture toughness for thin coatings," Journal of Physics D: Applied Physics, vol. 45, p. 203001, 2012.

[31] A. Volinsky, N. Moody, and W. Gerberich, "Interfacial toughness measurements for thin films on substrates," Acta materialia, vol. 50, pp. 441-466, 2002.

[32] G. Gioia and M. Ortiz, "Delamination of compressed thin films," Adv. Appl. Mech, vol. 33, pp. 119$192,1997$.

[33] H. M. Jensen and I. Sheinman, "Straight-sided, buckling-driven delamination of thin films at high stress levels," International Journal of Fracture, vol. 110, pp. 371-385, 2001.

[34] M. Moon, H. M. Jensen, J. W. Hutchinson, K. Oh, and A. Evans, "The characterization of telephone cord buckling of compressed thin films on substrates," Journal of the Mechanics and Physics of Solids, vol. 50, pp. 2355-2377, 2002.

[35] S.-J. Yu, X.-F. Xiao, M.-G. Chen, H. Zhou, J. Chen, P.-Z. Si, and Z.-W. Jiao, "Morphological selections and dynamical evolutions of buckling patterns in SiAlNx films: From straight-sided to telephone cord or bubble structures," Acta materialia, vol. 64, pp. 41-53, 2014.

[36] J. W. Hutchinson, "Delamination of compressed films on curved substrates," Journal of the Mechanics and Physics of Solids, vol. 49, pp. 1847-1864, 2001.

[37] M. J. Cordill, F. D. Fischer, F. G. Rammerstorfer, and G. Dehm, "Adhesion energies of Cr thin films on polyimide determined from buckling: Experiment and model," Acta materialia, vol. 58, pp. 55205531, 2010.

[38] M.-W. Moon, J.-W. Chung, K.-R. Lee, K. Oh, R. Wang, and A. Evans, "An experimental study of the influence of imperfections on the buckling of compressed thin films," Acta materialia, vol. 50, pp. 1219-1227, 2002.

[39] A. Evans and J. Hutchinson, "On the mechanics of delamination and spalling in compressed films," International Journal of Solids and Structures, vol. 20, pp. 455-466, 1984.

[40] H. M. Jensen and M. Thouless, "Buckling instability of straight edge cracks," Journal of applied mechanics, vol. 62, pp. 620-625, 1995.

[41] M. Thouless, J. Hutchinson, and E. Liniger, "Plane-strain, buckling-driven delamination of thin films: model experiments and mode-II fracture," Acta metallurgica et materialia, vol. 40, pp. 2639-2649, 1992.

[42] B. Audoly, "Mode-dependent toughness and the delamination of compressed thin films," Journal of the Mechanics and Physics of Solids, vol. 48, pp. 2315-2332, 2000.

[43] J. Hutchinson, M. He, and A. Evans, "The influence of imperfections on the nucleation and propagation of buckling driven delaminations," Journal of the Mechanics and Physics of Solids, vol. 48, pp. 709-734, 2000. 
[44] A. Evans, M. He, and J. Hutchinson, "Effect of interface undulations on the thermal fatigue of thin films and scales on metal substrates," Acta materialia, vol. 45, pp. 3543-3554, 1997.

[45] M. Zhao, J. Zhou, F. Yang, T. Liu, and T.-Y. Zhang, "Effects of substrate compliance on circular buckle delamination of thin films," Engineering Fracture Mechanics, vol. 74, pp. 2334-2351, 2007.

[46] Y. Ni and A. K. Soh, "On the growth of buckle-delamination pattern in compressed anisotropic thin films," Acta materialia, vol. 69, pp. 37-46, 5// 2014.

[47] P. Peyla, "Undulated blistering during thin film delamination," Physical Review E - Statistical Physics, Plasmas, Fluids, and Related Interdisciplinary Topics, vol. 62, pp. R1501-R1504, 2000.

[48] M. W. Moon, H. M. Jensen, J. W. Hutchinson, K. H. Oh, and A. G. Evans, "The characterization of telephone cord buckling of compressed thin films on substrates," Journal of the Mechanics and Physics of Solids, vol. 50, pp. 2355-2377, 2002.

[49] M. W. Moon, K. R. Lee, K. H. Oh, and J. W. Hutchinson, "Buckle delamination on patterned substrates," Acta materialia, vol. 52, pp. 3151-3159, 6/7/ 2004.

[50] M. Cordill, D. Bahr, N. Moody, and W. Gerberich, "Adhesion measurements using telephone cord buckles," Materials Science and Engineering: A, vol. 443, pp. 150-155, 2007.

[51] B. Cotterell and Z. Chen, "Buckling and cracking of thin films on compliant substrates under compression," International Journal of Fracture, vol. 104, pp. 169-179, 2000.

[52] H.-H. Yu, M. He, and J. Hutchinson, "Edge effects in thin film delamination," Acta Materialia, vol. 49, pp. 93-107, 2001.

[53] J. W. Hutchinson, "Mixed mode fracture mechanics of interfaces," Metal and Ceramic interfaces, pp. 295-306, 1990.

[54] D. Balint and J. Hutchinson, "Undulation instability of a compressed elastic film on a nonlinear creeping substrate," Acta materialia, vol. 51, pp. 3965-3983, 2003.

[55] A. R. Akisanya and N. A. Fleck, "The edge cracking and decohesion of thin films," International Journal of Solids and Structures, vol. 31, pp. 3175-3199, 12// 1994.

[56] B. Veluri and H. M. Jensen, "Steady-state propagation of interface corner crack," International Journal of Solids and Structures, vol. 50, pp. 1613-1620, 2013.

[57] M. G. Andrews and R. Massabò, "The effects of shear and near tip deformations on energy release rate and mode mixity of edge-cracked orthotropic layers," Engineering Fracture Mechanics, vol. 74, pp. 2700-2720, 2007.

[58] H. Beom, C. Cui, and H. Jang, "Dependence of elastic constants on stress intensity factors for cracks in an orthotropic bimaterial with a thin film," Int. J. Solids. Struct, vol. 49, pp. 3461-3471, 2012.

[59] S. J. Bull, "Nanoindentation of coatings," Journal of Physics D: Applied Physics, vol. 38, p. R393, 2005.

[60] J. D. Bressan, A. Tramontin, and C. Rosa, "Modeling of nanoindentation of bulk and thin film by finite element method," Wear, vol. 258, pp. 115-122, 1// 2005.

[61] M. Papini and J. Spelt, "The mechanics of coatings," Adhesion science and engineering-I: the mechanics of adhesion, New York: Elsevier, pp. 303-350, 2002.

[62] M. S. Hu and A. G. Evans, "The cracking and decohesion of thin films on ductile substrates," Acta Metallurgica, vol. 37, pp. 917-925, 1989/03/01 1989.

[63] A. Evans, M. Drory, and M. Hu, "The cracking and decohesion of thin films," Journal of materials research, vol. 3, pp. 1043-1049, 1988.

[64] T. Nakamura and S. M. Kamath, "Three-dimensional effects in thin film fracture mechanics," Mechanics of Materials, vol. 13, pp. 67-77, 1992.

[65] A. G. Evans, B. Dalgleish, M. He, and J. Hutchinson, "On crack path selection and the interface fracture energy in bimaterial systems," Acta metallurgica, vol. 37, pp. 3249-3254, 1989.

[66] J. Beuth, "Cracking of thin bonded films in residual tension," International Journal of Solids and Structures, vol. 29, pp. 1657-1675, 1992.

[67] J. L. Beuth and N. W. Klingbeil, "Cracking of thin films bonded to elastic-plastic substrates," Journal of the Mechanics and Physics of Solids, vol. 44, pp. 1411-1428, 1996.

[68] Z. C. Xia and J. W. Hutchinson, "Crack patterns in thin films," Journal of the Mechanics and Physics of Solids, vol. 48, pp. 1107-1131, 2000.

[69] T. Ye, Z. Suo, and A. G. Evans, "Thin film cracking and the roles of substrate and interface," International Journal of Solids and Structures, vol. 29, pp. 2639-2648, 1992/01/01 1992.

[70] Z. Suo and J. W. Hutchinson, "Steady-state cracking in brittle substrates beneath adherent films," International Journal of Solids and Structures, vol. 25, pp. 1337-1353, 1989.

[71] S. Schmauder and M. Meyer, "Correlation between Dundurs' parameters and elastic constants," $Z$. Metallkd, vol. 83, p. 525, 1992.

[72] T. Ye, Z. Suo, and A. Evans, "Thin film cracking and the roles of substrate and interface," International Journal of Solids and Structures, vol. 29, pp. 2639-2648, 1992. 
[73] M. Thouless, "Crack spacing in brittle films on elastic substrates," Journal of the American Ceramic Society, vol. 73, pp. 2144-2146, 1990.

[74] M. D. Thouless, E. Olsson, and A. Gupta, "Cracking of brittle films on elastic substrates," Acta metallurgica et materialia, vol. 40, pp. 1287-1292, 1992.

[75] Z. Chen, B. Cotterell, and W. Wang, "The fracture of brittle thin films on compliant substrates in flexible displays," Engineering Fracture Mechanics, vol. 69, pp. 597-603, 2002.

[76] V. Shenoy, A. Schwartzman, and L. Freund, "Crack patterns in brittle thin films," International journal of fracture, vol. 103, pp. 1-17, 2000.

[77] A. Strawbridge and H. E. Evans, "Mechanical failure of thin brittle coatings," Engineering Failure Analysis, vol. 2, pp. 85-103, 1995.

[78] J. J. Vlassak, "Channel cracking in thin films on substrates of finite thickness," International Journal of Fracture, vol. 119, pp. 299-323, 2003.

[79] R. Huang, J. H. Prévost, Z. Y. Huang, and Z. Suo, "Channel-cracking of thin films with the extended finite element method," Engineering Fracture Mechanics, vol. 70, pp. 2513-2526, 12// 2003.

[80] N. Sukumar and J. H. Prévost, "Modeling quasi-static crack growth with the extended finite element method Part I: Computer implementation," International Journal of Solids and Structures, vol. 40, pp. 7513-7537, 12// 2003.

[81] R. Krishnamurthy and D. J. Srolovitz, "Stress distributions in growing oxide films," Acta materialia, vol. 51, pp. 2171-2190, 5/7/ 2003.

[82] D. S. Gianola, S. Van Petegem, M. Legros, S. Brandstetter, H. Van Swygenhoven, and K. J. Hemker, "Stress-assisted discontinuous grain growth and its effect on the deformation behavior of nanocrystalline aluminum thin films," Acta Materialia, vol. 54, pp. 2253-2263, 5// 2006.

[83] U. Welzel, J. Ligot, P. Lamparter, A. Vermeulen, and E. Mittemeijer, "Stress analysis of polycrystalline thin films and surface regions by X-ray diffraction," Journal of Applied Crystallography, vol. 38, pp. 1-29, 2005.

[84] C.-H. Hsueh, "Modeling of elastic deformation of multilayers due to residual stresses and external bending," Journal of Applied Physics, vol. 91, pp. 9652-9656, 2002.

[85] P. Wellner, O. Kraft, G. Dehm, J. Andersons, and E. Arzt, "Channel cracking of $\beta$-NiAl thin films on Si substrates," Acta materialia, vol. 52, pp. 2325-2336, 5/3/ 2004.

[86] T. Guo, L. Qiao, X. Pang, and A. A. Volinsky, "Brittle film-induced cracking of ductile substrates," Acta materialia, vol. 99, pp. 273-280, 2015.

[87] M. D. Thouless, Z. Li, N. J. Douville, and S. Takayama, "Periodic cracking of films supported on compliant substrates," Journal of the Mechanics and Physics of Solids, vol. 59, pp. 1927-1937, 2011.

[88] N. Klingbeil and J. Beuth, "On the design of debond-resistant bimaterials: part I: free-edge singularity approach," Engineering Fracture Mechanics, vol. 66, pp. 93-110, 2000.

[89] N. Klingbeil and J. Beuth, "On the design of debond-resistant bimaterials: part II: a comparison of freeedge and interface crack approaches," Engineering Fracture Mechanics, vol. 66, pp. 111-128, 2000.

[90] D. Bogy, "On the problem of edge-bonded elastic quarter-planes loaded at the boundary," International Journal of Solids and Structures, vol. 6, pp. 1287-1313, 1970.

[91] D. B. Bogy, "Edge-bonded dissimilar orthogonal elastic wedges under normal and shear loading," Journal of applied mechanics, vol. 35, pp. 460-466, 1968.

[92] T. Suga, K. Mizuno, and K. Miyazawa, "Thermal stresses in ceramic-to-metal joints," in MRS International Meeting on Advanced Materials, 1 st, Tokyo, Japan, 1989, pp. 137-142.

[93] Y. Yang and D. Munz, "Stress singularities in a dissimilar materials joint with edge tractions under mechanical and thermal loadings," International Journal of Solids and Structures, vol. 34, pp. 11991216, 1997.

[94] K. Wu, J. Y. Zhang, J. Li, Y. Q. Wang, G. Liu, and J. Sun, "Length-scale-dependent cracking and buckling behaviors of nanostructured $\mathrm{Cu} / \mathrm{Cr}$ multilayer films on compliant substrates," Acta materialia, vol. 100, pp. 344-358, 11// 2015.

[95] G. Parry, A. Cimetière, C. Coupeau, J. Colin, and J. Grilhé, "Stability diagram of unilateral buckling patterns of strip-delaminated films," Physical Review E, vol. 74, p. 066601, 2006.

[96] P. A. Sørensen, S. Kiil, K. Dam-Johansen, and C. Weinell, "Anticorrosive coatings: a review," Journal of Coatings Technology and Research, vol. 6, pp. 135-176, 2009.

[97] T. Chuang, T. Nguyen, and S. Li, "A non-osmotic blister growth model in coating systems," in Damage and failure of interfaces. 1st International Conference. Proceedings, 1997, pp. 203-209.

[98] T.-J. Chuang, T. Nguyen, and S. Lee, "Micro-mechanic model for cathodic blister growth in painted steel," Journal of Coatings Technology, vol. 71, pp. 75-85, 1999.

[99] J. M. Pommersheim, T. Nguyen, and K. Hartzfeld, "Prediction of blistering in coating systems," in ACS Symposium Series, 1998, pp. 137-150. 
[100] J. W. Martin, Methodologies for predicting the service lives of coating systems vol. 172: DIANE Publishing, 1994.

[101] K.-t. Wan and K. Liao, "Measuring mechanical properties of thin flexible films by a shaft-loaded blister test," Thin Solid Films, vol. 352, pp. 167-172, 9/8/ 1999.

[102] J. Bressers, S. Peteves, and M. Steen, "Coatings for hot section gas turbine components," in European Structural Integrity Society. vol. Volume 26, M. E. A. M.-M. M. Fuentes and J. M. Martínez-Esnaola, Eds., ed: Elsevier, 2000, pp. 115-134.

[103] R. Escobar Galindo, A. van Veen, J. H. Evans, H. Schut, and J. T. M. de Hosson, "A modified blister test to study the adhesion of thin coatings based on local helium ion implantation," Thin Solid Films, vol. 471, pp. 170-176, 1/3/ 2005 .

[104] H. Jahnsen, "Delamination of coatings," Handbook of Materials behavior models, pp. 582-6, 2001.

[105] M. Kappes, G. S. Frankel, and N. Sridhar, "Adhesion and adhesion degradation of a pressure sensitive tape on carbon steel," Progress in Organic Coatings, vol. 69, pp. 57-62, 2010.

[106] Y. Prawoto and B. Dillon, "Failure analysis and life assessment of coating: the use of mixed mode stress intensity factors in coating and other surface engineering life assessment," Journal of failure analysis and prevention, vol. 12, pp. 190-197, 2012.

[107] Y. Prawoto, N. Kamsah, M. Mat Yajid, and Z. Ahmad, "Energy density mechanics applied to coating blistering problems," Theoretical and applied fracture mechanics, vol. 56, pp. 89-94, 2011.

[108] Y. Prawoto, "Unified model for blister growth in coating degradation using weight function and diffusion concepts," Materials and Corrosion, 2012.

[109] Y. Prawoto and I. H. Onn, "Modified Fourier solution for diffusion governing law applied to blister formation and development," Computational Materials Science, vol. 62, pp. 105-109, 2012.

[110] Y. Prawoto and I. H. Onn, "Application of $<\mathrm{i}>\mathrm{J}</ \mathrm{i}>$-integral concept on blister coating problem," Engineering Fracture Mechanics, vol. 92, pp. 114-125, 2012.

[111] F. Deflorian and S. Rossi, "An EIS study of ion diffusion through organic coatings," Electrochimica acta, vol. 51, pp. 1736-1744, 2006.

[112] M. Stratmann, A. Leng, W. Fürbeth, H. Streckel, H. Gehmecker, and K.-H. Große-Brinkhaus, "The scanning Kelvin probe; a new technique for the in situ analysis of the delamination of organic coatings," Progress in Organic Coatings, vol. 27, pp. 261-267, 1996.

[113] M. Stratmann, R. Feser, and A. Leng, "Corrosion protection by organic films," Electrochimica Acta, vol. 39, pp. 1207-1214, 1994.

[114] G. Grundmeier, C. Reinartz, M. Rohwerder, and M. Stratmann, "Corrosion properties of chemically modified metal surfaces," Electrochimica acta, vol. 43, pp. 165-174, 1998.

[115] A. Leng, H. Streckel, and M. Stratmann, "The delamination of polymeric coatings from steel. Part 1: Calibration of the Kelvinprobe and basic delamination mechanism," Corrosion Science, vol. 41, pp. 547-578, 1998.

[116] A. Leng, H. Streckel, and M. Stratmann, "The delamination of polymeric coatings from steel. Part 2: First stage of delamination, effect of type and concentration of cations on delamination, chemical analysis of the interface," Corrosion Science, vol. 41, pp. 579-597, 1998.

[117] A. Leng, H. Streckel, K. Hofmann, and M. Stratmann, "The delamination of polymeric coatings from steel Part 3: Effect of the oxygen partial pressure on the delamination reaction and current distribution at the metal/polymer interface," Corrosion Science, vol. 41, pp. 599-620, 1998.

[118] W. Fürbeth and M. Stratmann, "The delamination of polymeric coatings from electrogalvanized steel-a mechanistic approach.: Part 2: delamination from a defect down to steel," Corrosion Science, vol. 43, pp. 229-241, 2001.

[119] W. Fürbeth and M. Stratmann, "The delamination of polymeric coatings from electrogalvanized steel-a mechanistic approach.: Part 3: delamination kinetics and influence of CO2," Corrosion Science, vol. 43, pp. 243-254, 2001.

[120] G. Grundmeier, W. Schmidt, and M. Stratmann, "Corrosion protection by organic coatings: electrochemical mechanism and novel methods of investigation," Electrochimica Acta, vol. 45, pp. 2515-2533, 2000.

[121] K. Ogle, S. Morel, and N. Meddahi, "An electrochemical study of the delamination of polymer coatings on galvanized steel," Corrosion science, vol. 47, pp. 2034-2052, 2005.

[122] K. Ogle, A. Tomandl, N. Meddahi, and M. Wolpers, "The alkaline stability of phosphate coatings I: ICP atomic emission spectroelectrochemistry," Corrosion Science, vol. 46, pp. 979-995, 2004.

[123] A. Tomandl, M. Wolpers, and K. Ogle, "The alkaline stability of phosphate coatings II: in situ Raman spectroscopy," Corrosion science, vol. 46, pp. 997-1011, 2004.

[124] G. Sabde, "Study of current/potential distribution in a cathodically protected crevice," Ph. D. diss., Clarkson University, 1995. 
[125] D.-T. Chin and G. Sabde, "Modeling transport process and current distribution in a cathodically protected crevice," Corrosion, vol. 56, pp. 783-793, 2000.

[126] F. Song, D. Kirk, J. Graydon, and D. Cormack, "Steel corrosion under a disbonded coating with a holiday-Part 1: The model and validation," Corrosion, vol. 58, pp. 1015-1024, 2002.

[127] F. Song, D. Kirk, J. Graydon, and D. Cormack, "Steel corrosion under a disbonded coating with a holiday-Part 2: Corrosion behavior," Corrosion, vol. 59, pp. 42-49, 2003.

[128] K. N. Allahar, M. E. Orazem, and K. Ogle, "Mathematical model for cathodic delamination using a porosity-pH relationship," Corrosion Science, vol. 49, pp. 3638-3658, 2007.

[129] K. N. Allahar and M. E. Orazem, "On the extension of CP models to address cathodic protection under a delaminated coating," Corrosion Science, vol. 51, pp. 962-970, 2009.

[130] M.-W. Huang, C. Allely, K. Ogle, and M. E. Orazem, "A mathematical model for cathodic delamination of coated metal including a kinetic $\mathrm{pH}$-porosity relationship," Journal of the Electrochemical Society, vol. 155, pp. C279-C292, 2008.

[131] S. Sundararajan and B. Bhushan, "Micro/nanotribology of ultra-thin hard amorphous carbon coatings using atomic force/friction force microscopy," Wear, vol. 225-229, Part 1, pp. 678-689, 4// 1999.

[132] S. Izabela, C. Michael, and W. C. Robert, "Recent advances in single-asperity nanotribology," Journal of Physics D: Applied Physics, vol. 41, p. 123001, 2008.

[133] B. Bhushan, J. N. Israelachvili, and U. Landman, "Nanotribology: friction, wear and lubrication at the atomic scale," Nature, vol. 374, pp. 607-616, 1995.

[134] A. Fischer and S. Mischler, "Tribocorrosion: fundamentals, materials and applications," J. Phys. D: Appl. Phys, vol. 39, 2006.

[135] P. A. Dearnley and G. Aldrich-Smith, "Corrosion-wear mechanisms of hard coated austenitic 316L stainless steels," Wear, vol. 256, pp. 491-499, 2004.

[136] P. Ponthiaux, F. Wenger, D. Drees, and J.-P. Celis, "Electrochemical techniques for studying tribocorrosion processes," Wear, vol. 256, pp. 459-468, 2004.

[137] I. Garcia, D. Drees, and J.-P. Celis, "Corrosion-wear of passivating materials in sliding contacts based on a concept of active wear track area," Wear, vol. 249, pp. 452-460, 2001.

[138] J. R. Goldberg and J. L. Gilbert, "Electrochemical response of CoCrMo to high-speed fracture of its metal oxide using an electrochemical scratch test method," Journal of biomedical materials research, vol. 37, pp. 421-431, 1997.

[139] S. Mischler, A. Spiegel, and D. Landolt, "The role of passive oxide films on the degradation of steel in tribocorrosion systems," Wear, vol. 225, pp. 1078-1087, 1999.

[140] J. Jiang, M. Stack, and A. Neville, "Modelling the tribo-corrosion interaction in aqueous sliding conditions," Tribology International, vol. 35, pp. 669-679, 2002.

[141] B. Bozzini, M. E. Ricotti, M. Boniardi, and C. Mele, "Evaluation of erosion-corrosion in multiphase flow via CFD and experimental analysis," Wear, vol. 255, pp. 237-245, 2003.

[142] T. Nguyen, J. Hubbard, and J. Pommersheim, "Unified model for the degradation of organic coatings on steel in a neutral electrolyte," JCT, Journal of coatings technology, vol. 68, pp. 45-56, 1996. 